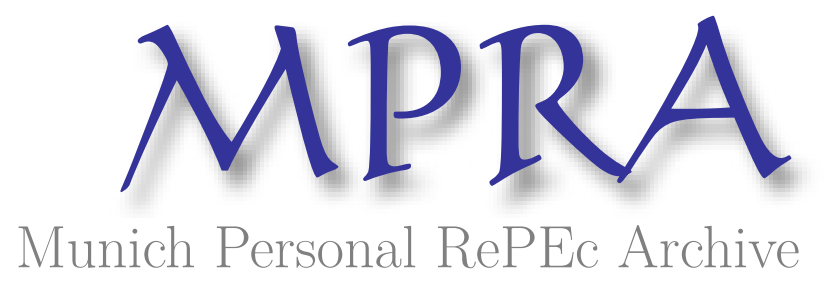

\title{
The optimal design of a fiscal union
}

Dmitriev, Mikhail and Hoddenbagh, Jonathan

December 2012

Online at https://mpra.ub.uni-muenchen.de/46007/

MPRA Paper No. 46007, posted 09 Apr 2013 14:21 UTC 


\title{
The Optimal Design Of A Fiscal Union*
}

\author{
Mikhail Dmitriev ${ }^{\dagger}$ and Jonathan Hoddenbagh ${ }^{\ddagger}$
}

First Draft: December, 2012 This Version: March, 2013

We study the optimal design of a fiscal union within a currency union using an open economy model with nominal rigidities. We show that the optimal design of a fiscal union depends crucially on the degree of financial integration across countries as well as the elasticity of substitution between domestic and foreign goods. Empirical estimates of substitutability range between 1 and 12. If substitutability is low (around 1), risk-sharing occurs naturally via terms of trade movements even in financial autarky, country-level monopoly power is high and losses from terms of trade externalities dominate other distortions. On the other hand, if substitutability is high (greater than 1), risk-sharing does not occur naturally via terms of trade movements, country-level monopoly power is low and losses from nominal rigidities dominate other distortions. We show that members of a fiscal union should (1) coordinate labor and consumption taxes when substitutability is low to eliminate terms of trade distortions, and (2) coordinate contingent cross-country transfers when substitutability is high to improve risk-sharing, particularly when union members lose access to international financial markets. Contingent fiscal policy at the national level is also necessary to eliminate nominal rigidities in the presence of asymmetric shocks, and yields large welfare gains when goods are close substitutes.

Keywords: Open economy macroeconomics; Optimal policy; Fiscal unions; Currency unions.

JEL Classification Numbers: E50, F41, F42.

\footnotetext{
*This paper grew out of our shared experience in the International Macroeconomics course taught by Fabio Ghironi, to whom we owe a great debt of gratitude for advice and support. We thank Eyal Dvir and Susanto Basu for helpful comments, as well as seminar participants at Boston College. Any errors are our own.

${ }^{\dagger}$ Department of Economics, Boston College, Chestnut Hill, MA 02467. E-mail: dmitriev@bc.edu.

${ }^{\ddagger}$ Department of Economics, Boston College, Chestnut Hill, MA 02467. E-mail: jon.hoddenbagh@gmail.com.
} 


\section{Introduction}

The recent crisis in the euro area has revealed the shortcomings of a currency union that fails to adequately monitor and coordinate fiscal policy across members. This has prompted much debate about the need for a fiscal union within the euro area.

We study the optimal design of a fiscal union within a currency union using an open economy model with nominal rigidities, similar to the dynamic model employed in Gali and Monacelli (2005, 2008) and Farhi and Werning (2012). Different from other research in this literature, we obtain a global closed-form solution of the model for non-unitary elasticity of substitution between domestic and foreign products. This allows us to accurately compare welfare across a variety of risk-sharing regimes, including complete markets and financial autarky, which is not possible when standard methods are employed to answer such questions. ${ }^{1}$

Using our global closed form solution, we show that the relative need for and the optimal design of a fiscal union depends crucially on the level of cross-country risk-sharing provided by international financial markets as well as the elasticity of substitution between domestic and foreign products. Empirical estimates of substitutability range between one (macro estimates) and twelve (micro estimates). ${ }^{2}$

When substitutability is low (around one), cross-country risk-sharing occurs naturally via terms of trade movements, even in financial autarky. As such, internationally complete asset markets are redundant, as are contingent transfers within a fiscal union: both are unnecessary to ensure cross-country risk-sharing. Countries have a relatively high degree of monopoly power when substitutability is low, which generates large terms of trade externalities. The optimal fiscal union in such cases will remove the incentive for national policymakers to manipulate their terms of trade by coordinating steady state labor tax rates. If preferences are identical across countries, this will result in the establishment of a common labor tax rate. We refer to this as a tax union.

When substitutability is high (greater than one), cross-country risk-sharing no longer occurs naturally via terms of trade movements. If financial integration is low or countries lose access to international financial markets, there will be no risk-sharing across countries. The optimal role of a fiscal union in such cases is to step in and provide risk-sharing via contingent crosscountry transfers. We refer to this as a transfer union. Transfer unions are especially important

\footnotetext{
${ }^{1}$ We detail the technical advantages of our framework later in the paper, but start by introducing our main findings.

${ }^{2} \mathrm{~A}$ non-exhaustive list of papers that provide estimates of the elasticity of substitution includes Feenstra, Obstfeld and Russ (2010), Imbs and Majean (2009)), and Lai and Trefler (2002).
} 
when members of a currency union lose access to international financial markets. In addition, when substitutability is high, country level monopoly power is small because goods are easily substitutable. Losses from terms of trade manipulation thus diminish in importance relative to other distortions as substitutability increases. Nominal rigidities now take center stage, leading to large welfare losses when left unchecked.

Within a currency union, the union-wide central bank is unable to eliminate these nominal rigidities in the presence of asymmetric shocks across countries, which prevents efficient adjustment of the economy through changes in relative prices. While this role is fulfilled by national central banks when exchange rates are flexible, a common union-wide central bank has only one instrument to fight many idiosyncratic shocks. ${ }^{3}$ National fiscal authorities within a currency union therefore have a role to play in implementing contingent policies that move the economy toward the efficient level of output and eliminate nominal rigidities. Importantly, such policies do not require international fiscal coordination.

\section{Related Literature}

This paper is related to the literature on the conduct of optimal monetary and fiscal policy among interdependent economies, particularly within a currency union. Early non-microfounded contributions in this area include Canzoneri and Henderson (1990) and Eichengreen and Ghironi (2002). Microfounded models, including those developed by Beetsma and Jensen (2005), Bottazzi and Manasse (2005), Gali and Monacelli (2008) and Ferrero (2009), focus primarily on the case of cooperative policy with internationally complete asset markets. Later work by Benigno and De Paoli (2010) emphasizes the international dimension of fiscal policy for the case of a small open economy, abstracting from the role of strategic interactions between countries.

Closest to our paper is recent work by Farhi and Werning (2012) on fiscal unions within a currency union. They demonstrate that even when private asset markets are complete internationally, there is a role for contingent cross country transfers to provide consumption insurance. They also show that the benefits of a transfer union are greater within a currency union than outside of one. When solving for optimal policy in their dynamic model, they log-linearize around the Cole-Obstfeld (1991) steady state, assuming unitary elasticity of substitution between goods across countries as well as log utility. ${ }^{4}$ As Cole and Obstfeld show, unitary elasticity implies perfect risk-sharing across countries even when international asset

\footnotetext{
${ }^{3}$ Note that if shocks are symmetric across countries, the union wide central bank is able to eliminate nominal rigidities and mimic the flexible price equilibrium.

${ }^{4}$ In our notation, this assumption implies the following calibration: $\gamma=\sigma=1$.
} 
markets are incomplete. We depart from the Cole-Obstfeld case and examine the impact of non-unitary elasticity of substitution on the optimal design of a fiscal union. We also divide the concept of a fiscal union into two components, analyzing the welfare implications of both a tax union and a transfer union, whereas Farhi and Werning examine the impact of a transfer union but not a tax union.

We claimed earlier that standard models are unable to fully evaluate the optimal design of a fiscal union. There are two reasons for this. First, log-linear approximations are only accurate near their steady state, but in the presence of terms of trade externalities, different steady states will arise depending on whether policymakers are cooperating or not. As a result, welfare comparisons between cooperative and non-cooperative regimes in log-linear models are inaccurate, preventing rigorous analysis of the gains from monetary and fiscal policy cooperation across countries. ${ }^{5}$ Second, tractable two-country global solutions fall short because they must assume unitary elasticity of substitution between home and foreign goods. As we've already mentioned, unitary elasticity implies complete risk-sharing across countries via terms-of-trade movements, so that households face no idiosyncratic consumption risk in complete markets, incomplete markets or financial autarky. Counterfactually, under unitary elasticity export revenues are constant and immune to exchange rate fluctuations and productivity shocks. Financial market structure has no impact on the equilibrium allocation in models with unitary elasticity. So we have a conundrum: log-linearization does not allow for accurate welfare comparisons across different steady states, while tractable two-country global methods have undesirable properties due to unitary elasticity.

We resolve this conundrum, and develop a tractable closed-form model with non-unitary elasticity for a continuum of small open economies. We solve the model in closed form and calculate the exact welfare gains resulting from fiscal cooperation across countries in the form of a tax union and a transfer union. ${ }^{6}$ Our framework does not face the problems encountered when conducting such an exercise in a log-linear model. Crucially, when substitutability differs from one, the equilibrium outcome across countries depends on the degree of financial integration, as well as the conduct of monetary and fiscal policy. We conduct these experiments for both flexible

${ }^{5}$ This is one reason why there was such an emphasis on closed-form solutions in the early micro-founded literature on international policy cooperation. See Corsetti and Pesenti (2001, 2005), Devereux and Engel (2003) and Obstfeld and Rogoff (2001, 2002).

${ }^{6}$ In a related paper (Dmitriev and Hoddenbagh (2013)) we study international monetary cooperation and show that monetary cooperation in this model does not improve welfare. The non-cooperative central bank Nash equilibrium is identical with the cooperative Nash equilibrium in all cases examined: under PCP and LCP, in financial autarky and complete markets. Our focus here is on fiscal policy cooperation, particularly within a currency union. 
exchange rate regimes and within currency unions, in both complete markets and financial autarky, for cooperative and non-cooperative equilibria. To our knowledge, we provide the first unifying micro-founded framework for the analysis of fiscal and monetary policy cooperation and financial integration across countries in a model where financial market structure matters.

\section{The Model}

We consider a continuum of small open economies represented by the unit interval, as popularized in the literature by Gali and Monacelli $(2005,2008)$. Our model is based on Dmitriev and Hoddenbagh (2013), although here we consider wage rigidity rather than price rigidity.

Each economy consists of a representative household and a representative firm. All countries are identical ex-ante: they have the same preferences, technology, and wage-setting. Ex-post, economies will differ depending on the realization of their technology shock. Households are immobile across countries, however goods can move freely across borders. Each economy produces one final good, over which it exercises a degree of monopoly power. This is crucially important: countries are able to manipulate their terms of trade even though they are measure zero. As in Corsetti and Pesenti (2001, 2005) and Obstfeld and Rogoff (2000, 2002), we ignore capital and use one-period-in-advance wage setting to introduce nominal rigidities. Workers set next period's nominal wages, in terms of domestic currency, prior to next-period's production and consumption decisions. Given this preset wage, workers supply as much labor as demanded by firms. We lay out a general framework below, and then hone in on the specific case of complete markets and financial autarky. To avoid additional notation, we ignore time subindices unless absolutely necessary. When time subindices are absent, we are implicitly referring to period $t$.

Production Each economy $i$ produces a final good, which requires technology, $Z_{i}$, and aggregated labor, $N_{i}$. We assume that technology is independent across time and across countries. We need not impose any particular distributional requirement on technology at this point. The production function of each economy will be:

$$
Y_{i}=Z_{i} N_{i}
$$

Households, indexed by $h$, each have some monopoly control over their labor input, which will lead to a markup in wages. Perfectly competitive goods producers aggregate the labor input 
of each household, so that production of the representative firm in a specific country is: ${ }^{7}$

$$
N_{i}=\left(\int_{0}^{1} N_{i}(h)^{\frac{\varepsilon-1}{\varepsilon}} d h\right)^{\frac{\varepsilon}{\varepsilon-1}}
$$

where $\varepsilon$ is the elasticity of substitution between different types of labor, and $\mu=\frac{\varepsilon}{\varepsilon-1}$ is the markup.

The aggregate labor cost index, $W$, defined as the minimum cost to produce one unit of output, will be a function of the nominal wage for household $h, W(h)$ :

$$
W_{i}=\left(\int_{0}^{1} W_{i}(h)^{1-\varepsilon} d h\right)^{\frac{1}{1-\varepsilon}}
$$

Cost minimization by the firm leads to demand for labor from household $h$ :

$$
N_{i}(h)=\left(\frac{W_{i}(h)}{W_{i}}\right)^{-\varepsilon} N_{i}
$$

In the open economy, monopoly power may be exercised at both the household and the country level: at the household level because of differentiated labor, and at the country level because each economy produces only one unique good. Country-specific policymakers can thus manipulate their terms of trade via fiscal or monetary policy. Firms have no monopoly power and are perfectly competitive.

Households In each economy, there is a household, $h$, with lifetime expected utility

$$
\mathbb{E}_{t-1}\left\{\sum_{k=0}^{\infty} \beta^{k}\left(\frac{C_{i t+k}(h)^{1-\sigma}}{1-\sigma}-\chi \frac{N_{i t+k}(h)^{1+\varphi}}{1+\varphi}\right)\right\}
$$

where $\beta<1$ is the household discount factor, $C(h)$ is the consumption basket or index, $N(h)$ is household labor effort (think of this as hours worked). Households face a general budget constraint that nests both complete markets and financial autarky; we will discuss the differences between the two in subsequent sections. For now, it is sufficient to simply write out the most general form of the budget constraint:

$$
C_{i t}(h)=\left(1-\tau_{i}\right)\left(\frac{W_{i t}(h)}{P_{i t}(h)}\right) N_{i t}(h)+\mathcal{D}_{i t}(h)+\mathcal{T}_{i t}(h)+\Gamma_{i t}(h)
$$

\footnotetext{
${ }^{7}$ To be crystally clear, households have monopoly power while firms do not.
} 
The distortionary tax rate on household labor income in country $i$ is denoted by $\tau_{i}$, while $\Gamma_{i t}$ is a domestic lump-sum tax rebate households. $\mathcal{T}$ refers to lump-sum cross-country transfers. In the absence of a fiscal union, these cross-country transfers will equal zero $(\mathcal{T}=0)$. Net taxes equal zero in the model, as any amount of government revenue is rebated lump-sum to households. The consumer price index corresponds to $P_{i t}$, while the nominal wage is $W_{i t}$. $\mathcal{D}_{i t}$ denotes state-contingent portfolio payments expressed in real consumption units, and can be written in more detail as:

$$
\mathcal{D}_{i t} P_{i t}=\int_{0}^{1} \mathcal{E}_{i j t} B_{i j t} d j,
$$

where $B_{i j t}$ is a state-contingent payment in currency $j .{ }^{8} \mathcal{E}_{i j t}$ is the exchange rate in units of currency $i$ per one unit of currency $j$; an increase in $\mathcal{E}_{i j t}$ signals a depreciation of currency $i$ relative to currency $j$. When international asset markets are complete, households perform all cross-border trades in contingent claims in period 0, insuring against all possible states in all future periods. The transverality condition simply states that all period 0 transactions must be balanced: payment for claims issued must equal payment for claims received. Leaving the details in the appendix, we use the following relationship as the transversality condition for complete markets:

$$
\mathbb{E}_{0}\left\{\sum_{t=0}^{\infty} \beta^{t} C_{i t}^{-\sigma} \mathcal{D}_{i t}\right\}=0
$$

while in financial autarky

$$
\mathcal{D}_{i t}=0
$$

Intuitively, the transversality condition (7) stipulates that the present discounted value of future earnings should be equal to the present discounted value of future consumption flows. Under complete markets, consumers choose a state contingent plan for consumption, labor supply and portfolio holdings in period 0 .

Consumption and Price Indices Households in each country consume a basket of imported goods. This consumption basket is an aggregate of all of the varieties produced by different countries. The consumption basket for a representative small open economy $i$, which is common

\footnotetext{
${ }^{8}$ Equation (6) holds in all possible states in all periods. Details are provided in Appendix A.1.
} 
across countries, is defined as follows:

$$
C_{i}=\left(\int_{0}^{1} c_{i j}^{\frac{\gamma-1}{\gamma}} d j\right)^{\frac{\gamma}{\gamma-1}}
$$

where lower case $c_{i j}$ is the consumption by country $i$ of the final good produced by country $j$, and $\gamma$ is the elasticity of substitution between domestic and foreign goods (the Armington elasticity). Because there is no home bias in consumption, countries will export all of the output of their unique variety, and import varieties from other countries to assemble the consumption basket.

Prices are defined as follows: lower case $p_{i j}$ denotes the price in country $i$ (in currency $i$ ) of the unique final good produced in country $j$, while upper case $P_{i}$ is the aggregate consumer price index in country $i$. Given the above consumption index, the consumer price index will be:

$$
P_{i}=\left(\int_{0}^{1} p_{i j}^{1-\gamma} d j\right)^{\frac{1}{1-\gamma}} .
$$

Consumption by country $i$ of the unique variety produced by country $j$ is:

$$
c_{i j}=\left(\frac{p_{i j}}{P_{i}}\right)^{-\gamma} C_{i}
$$

We assume that producer currency pricing (PCP) holds, and that the law of one price (LOP) holds, so that the price of the same good is equal across countries when converted into a common currency. We define the nominal bilateral exchange rate between countries $i$ and $j, \mathcal{E}_{i j}$, as units of currency $i$ per one unit of currency $j$. LOP requires that:

$$
p_{i j}=\mathcal{E}_{i j} p_{j j}
$$

Given LOP and identical preferences across countries, PPP will also hold for all $i, j$ country pairs:

$$
P_{i}=\mathcal{E}_{i j} P_{j}
$$

The terms of trade for country $j$ will be:

$$
T O T_{j}=\frac{p_{j j}}{P_{j}}
$$

where $T O T_{j}$ is defined as the home currency price of exports over the home currency price 
of imports. Now we can take (10), and using (11) and (12), solve for demand for country $j$ 's unique variety:

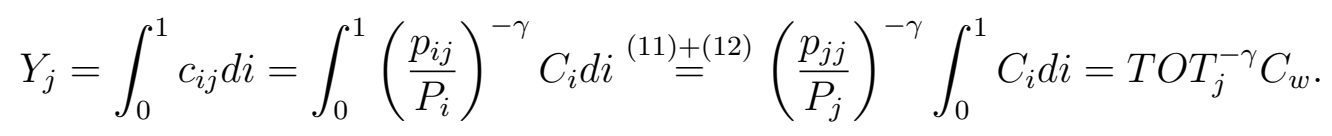

where $C_{w}$ is defined as the average world consumption across all $i$ economies, $C_{w}=\int_{0}^{1} C_{i} d i$.

Labor Market Clearing Households maximize (4) subject to (5). The first order condition for labor will give the optimal preset wage (that is, the labor supply condition):

$$
W_{i t}=\left(\frac{\chi \mu}{1-\tau_{i}}\right) \frac{\mathbb{E}_{t-1}\left\{N_{i t}^{1+\varphi}\right\}}{\mathbb{E}_{t-1}\left\{\frac{C_{i t}^{-\sigma} N_{i t}}{P_{i t}}\right\}}
$$

The optimization problem of the representative firm in country $i$ is standard. It maximizes profit choosing the appropriate amount of aggregate labor.

$$
\max _{N_{i}} Y_{i} p_{i}-W_{i} N_{i} \Rightarrow \frac{W_{i}}{p_{i}}=\frac{Y_{i}}{N_{i}}=Z_{i}
$$

This labor demand condition equates the real wage at time $t$ with the marginal product of labor, $Z_{i t}$. Using the labor demand condition $\left(N_{i t}=Y_{i t} p_{i t} / W_{i t}\right)$ from (16), and the fact that the wage is preset at time $t-1$, the labor market clearing condition will be:

$$
1=\left(\frac{\chi \mu}{1-\tau}\right) \frac{\mathbb{E}_{t-1}\left\{N_{i t}^{1+\varphi}\right\}}{\mathbb{E}_{t-1}\left\{C_{i t}^{-\sigma} Y_{i t} \frac{p_{i t}}{P_{i t}}\right\}}
$$

This is the general labor market clearing condition; it holds for the closed economy and in the open economy for producer currency pricing and local currency pricing. Under producer currency pricing, our focus in this paper, the demand for the unique variety (14) will give the following labor market clearing condition:

$$
1=\left(\frac{\chi \mu}{1-\tau}\right) \frac{\mathbb{E}_{t-1}\left\{N_{i t}^{1+\varphi}\right\}}{\mathbb{E}_{t-1}\left\{C_{i t}^{-\sigma} Y_{i t}^{\frac{\gamma-1}{\gamma}} C_{w t}^{\frac{1}{\gamma}}\right\}}
$$

Taking the expectations operator out of (18) will give the flexible wage equilibrium.

We now turn our attention to the difference between complete markets and financial autarky. 


\subsection{Complete Markets}

In this section, we assume that agents in each economy trade a full set of domestic and foreign state-contingent assets. Before any shocks are realized, national fiscal authorities declare non state-contingent taxes, and then national central banks declare money supply for all states of the world. With this knowledge in hand, households lay out a state-contingent plan for consumption, labor, money and asset holdings. After that, shocks hit the economy.

\begin{tabular}{|c|c|c|c|}
\hline-1 & 0 & 1 & $\mathrm{t}$ \\
\hline $\begin{array}{l}\text { Policymaker } \\
\text { declares } \\
\text { fiscal and } \\
\text { monetary } \\
\text { policy }\end{array}$ & $\begin{array}{c}\text { Household } \\
\text { makes } \\
\text { state-contingent } \\
\text { plan }\end{array}$ & $\begin{array}{l}\text { Period } 1 \\
\text { shocks are } \\
\text { realized }\end{array}$ & $\begin{array}{l}\text { Period } t \text { shocks } \\
\text { are realized }\end{array}$ \\
\hline
\end{tabular}

Households in all countries will maximize (4), choosing consumption, leisure, money holdings, and a complete set of state-contingent nominal bonds, subject to (5).

Risk-Sharing Complete markets and PPP imply the following risk-sharing condition:

$$
\frac{C_{i t}^{-\sigma}}{C_{i t+1}^{-\sigma}}=\frac{C_{j t}^{-\sigma}}{C_{j t+1}^{-\sigma}} \quad \forall i, j
$$

which states that the ratio of the marginal utility of consumption at time $t$ and $t+1$ must be equal across all countries. Importantly, this condition does not imply that consumption is equal across countries. Consumption in country $i$ will depend on its initial asset position, fiscal and monetary policy, the distribution of country-specific shocks, the covariance of global and local shocks, and other factors.

When policy maker in economy $i$ changes his policy, in response consumption allocation in country $i$ can change. For example, monetary policy can affect covariance between home production and world consumption, that covariance will affect the level of consumption of home household even under complete markets. Fiscal policy can tax consumption and cause lower level of consumption in the long-run relative to the rest of the world. However, it is still possible to characterize consumption plan robust to monetary and fiscal policy.

Definition 1 When (7),(17), and (19) hold, consumption in country $i$ can be expressed as a function of world consumption.

$$
C_{i t}=\frac{\mathbb{E}_{t-1}\left\{\sum \beta^{s}\left[Y_{i t+s} C_{w t+s}^{-\sigma} T O T_{i t+s}\right]\right\}}{\mathbb{E}_{t-1}\left\{\sum \beta^{s} C_{w t+s}^{1-\sigma}\right\}} C_{w t}
$$

This is our definition of complete markets. 
Using the fact that $Z_{i t}$ is independent across time and space, and prices are preset, (20) is equivalent to

$$
C_{i t}=\mathbb{E}_{t-1}\left\{Y_{i t} T O T_{i t}\right\}=C_{w}^{\frac{1}{\gamma}} \mathbb{E}_{t-1}\left\{Y_{i t}^{\frac{\gamma-1}{\gamma}}\right\}
$$

Note that there is no need for cross-country fiscal transfers in complete markets because perfect consumption risk-sharing results from trade in contingent claims.

\subsection{Financial Autarky}

The aggregate resource constraint under financial autarky specifies that the nominal value of output in the home country (exports) must equal the nominal of consumption in the home country (imports). That is, trade in goods must be balanced. In a model with cross-border lending, bonds would also show up in this condition, but in financial autarky, they are obviously absent. The primary departure from complete markets lies in the household and economy-wide budget constraints,

$$
\underbrace{P_{i} \cdot C_{i}}_{\text {Imports }}=\underbrace{p_{i i} \cdot Y_{i}}_{\text {Exports }}+\underbrace{\mathcal{T}_{i t}}_{\text {Transfers }}
$$

where transfers across countries will be zero in the absence of a transfer union. Using the fact that (14) holds under both complete markets and financial autarky, and substituting this into (22), one can show that demand for country $i$ 's good in financial autarky will be

$$
C_{i t}=C_{w}^{\frac{1}{\gamma}} Y_{i t}^{\frac{\gamma-1}{\gamma}}+\mathcal{T}_{i t}
$$

Complete markets and autarky differ only by goods market clearing. In complete markets consumption is equal to expected domestic output expressed in consumption baskets; in autarky consumption is equal to realized domestic output expressed in consumption baskets.

\section{Global Social Planner}

We begin by describing the maximization problem faced by a global social planner. The global social planner may be viewed as a benevolent supranational policymaker that has complete control over the monetary and fiscal policies of each country. The solution to the global social planner problem will yield the Pareto efficient equilibrium. Since the economies in our model are identical ex-ante, the global social planner will maximize a weighted utility function over all $i$ countries,

$$
\int_{0}^{1}\left[\frac{C_{i}^{1-\sigma}}{1-\sigma}-\chi \frac{N_{i}^{1+\varphi}}{(1+\varphi)}\right] d i
$$


subject to the consumption basket and the aggregate resource constraint:

$$
\begin{aligned}
C_{i} & =\left(\int_{0}^{1} c_{i j}^{\frac{\gamma-1}{\gamma}} d j\right)^{\frac{\gamma}{\gamma-1}}, \\
Y_{i} & =N_{i} Z_{i}=\int_{0}^{1} c_{j i} d j .
\end{aligned}
$$

Proposition 1 The global social planner will maximize utility weighted over all $i$ countries (24), subject to (25) and (26). The solution to this problem will yield the Pareto efficient allocation, detailed below:

$$
\begin{aligned}
& \mathbb{E}\left\{U_{i}\right\}=C_{i}^{1-\sigma}\left(\frac{1}{1-\sigma}-\frac{1}{1+\varphi}\right), \\
& C_{i}=\left(\frac{1}{\chi}\right)^{\frac{1}{\sigma+\varphi}} Z_{w}^{\frac{1+\varphi}{\sigma+\varphi}}, \\
& N_{i}=\left(\frac{1}{\chi}\right)^{\frac{1}{\sigma+\varphi}} Z_{w}^{\frac{(1-\gamma \sigma)(1+\varphi)}{(1+\gamma \varphi)(\sigma+\varphi)}} Z_{i}^{\frac{\gamma-1}{1+\gamma \varphi}}, \\
& Y_{i}=\left(\frac{1}{\chi}\right)^{\frac{1}{\sigma+\varphi}} Z_{w}^{\frac{(1-\gamma \sigma)(1+\varphi)}{(1+\gamma \varphi)(\sigma+\varphi)}} Z_{i}^{\frac{\gamma(1+\varphi)}{1+\gamma \varphi}}, \\
& Z_{w}=\left(\int_{0}^{1} Z_{i}^{\frac{(\gamma-1)(1+\varphi)}{1+\gamma \varphi}} d i\right)^{\frac{1+\gamma \varphi}{(\gamma-1)(1+\varphi)}} .
\end{aligned}
$$

Proof See Appendix.

The Pareto efficient allocation is a natural benchmark for the evaluation of different policy regimes. Notice that there are no markups: the benevolent global social planner has eliminated the markup on intermediate goods $\left(\mu_{\epsilon}=\frac{\epsilon}{1-\epsilon}\right)$, and resisted the temptation to impose a terms of trade markup $\left(\mu_{\gamma}=\frac{\gamma}{1-\gamma}\right)$. Idiosyncratic consumption risk has also been eliminated. This is exhibited by the absence of idiosyncratic technology $Z_{i}$ in $(\mathrm{A} .7 \mathrm{~b})$. In the next sections we will look closely at optimal monetary and fiscal policy and see what conditions are necessary to replicate the Pareto efficient allocation outside of and within a currency union.

\section{Non-Cooperative Policy}

In order to study the benefits of international policy cooperation, we must first consider the welfare losses resulting from optimal fiscal and monetary policy without cooperation. The goal of this section is to illuminate the various distortions that arise in a non-cooperative Nash equilibrium, comparing and contrasting with the global social planner equilibrium. We can then point out specific areas of policy cooperation that alleviate welfare decreasing distortions. 
To begin, we consider only non-contingent fiscal policy. At the end of this section we consider the implications of contingent fiscal policy and its differing effects under flexible exchange rates and within currency unions.

\subsection{Flexible Exchange Rates}

When exchange rates are flexible, each country has its own central bank and its own fiscal authority. Without loss of generality, we assume a cashless limiting economy. ${ }^{9}$ Central banks set monetary policy in each period by optimally choosing the amount of labor. Although central banks optimize by choosing labor instead of using an interest rate rule, the two are equivalent in this model. We can easily write down an interest rate rule that exactly gives the same allocation. Domestic fiscal authorities choose the optimal labor tax rate $\tau_{i}$. The objective function for non-cooperative domestic policymakers will be

$$
\max _{N_{i t}} \max _{\tau_{i}} \mathbb{E}_{t-1}\left\{\frac{C_{i t}^{1-\sigma}}{1-\sigma}-\chi \frac{N_{i t}^{1+\varphi}}{1+\varphi}\right\}
$$

where the fiscal authority acts first and chooses $\tau_{i}$ and the central bank then chooses $N_{i t}$.

We first examine the Nash equilibrium for non-cooperative policymakers when international asset markets are complete. Policymakers in complete markets will maximize their objective function subject to the labor market clearing (29a) and goods market clearing (29b) constraints, and production (29c) and aggregate world consumption (29d):

$$
\begin{aligned}
& 1=\left(\frac{\chi \mu}{1-\tau_{i}}\right) \frac{\mathbb{E}_{t-1}\left\{N_{i t}^{1+\varphi}\right\}}{\mathbb{E}_{t-1}\left\{C_{i t}^{-\sigma} Y_{i t}^{\frac{\gamma-1}{\gamma}} C_{w t}^{\frac{1}{\gamma}}\right\}}, \\
& C_{i t}=C_{w t}^{\frac{1}{\gamma}} \mathbb{E}_{t-1}\left\{Y_{i t}^{\frac{\gamma-1}{\gamma}}\right\} \\
& Y_{i t}=Z_{i t} N_{i t}, \\
& C_{w t}=\left(\int_{0}^{1} Y_{i t}^{\frac{\gamma-1}{\gamma}}\right)^{\frac{\gamma}{\gamma-1}} .
\end{aligned}
$$

Proposition 2 Flexible Exchange Rates + Complete Markets When international asset markets are complete and exchange rates are flexible, non-cooperative policymakers will maximize (28) subject to (29a), (29b), (29c) and (29d). The solution under commitment for

\footnotetext{
${ }^{9}$ Benigno and Benigno (2003) describe a cashless-limiting economy in detail in their appendix, pp.756-758.
} 
non-cooperative policymakers in complete markets is:

$$
\begin{aligned}
& \mathbb{E}\left\{U_{i}\right\}=C_{i}^{1-\sigma}\left[\frac{1}{1-\sigma}-\frac{1}{\mu_{\gamma}(1+\varphi)}\right] \\
& C_{i}=\left(\frac{1}{\chi \mu_{\gamma}}\right)^{\frac{1}{\sigma+\varphi}} Z_{w}^{\frac{1+\varphi}{\sigma+\varphi}} \\
& N_{i}=\left(\frac{1}{\chi \mu_{\gamma}}\right)^{\frac{1}{\sigma+\varphi}} Z_{w}^{\frac{(1-\gamma \sigma)(1+\varphi)}{(1+\gamma)(\sigma+\varphi)}} Z_{i}^{\frac{\gamma-1}{1+\gamma \varphi}} \\
& Y_{i}=\left(\frac{1}{\chi \mu_{\gamma}}\right)^{\frac{1}{\sigma+\varphi}} Z_{w}^{\frac{(1-\gamma \sigma)(1+\varphi)}{(1+\gamma \varphi)(\sigma+\varphi)}} Z_{i}^{\frac{\gamma(1+\varphi)}{1+\gamma \varphi}} \\
& Z_{w}=\left(\int_{0}^{1} Z_{i}^{\frac{(\gamma-1)(1+\varphi)}{1+\gamma \varphi}} d i\right)^{\frac{1+\gamma \varphi}{(\gamma-1)(1+\varphi)}}
\end{aligned}
$$

The resulting equilibrium allocation exactly coincides with the flexible wage allocation in complete markets, with the addition of a terms of trade markup. It is optimal for non-cooperative central banks under commitment to mimic the flexible wage allocation. The optimal tax rate for non-cooperative fiscal authorities is $\tau_{i}=1-\frac{\mu}{\mu_{\gamma}}$.

Proof See Appendix.

The above allocation replicates the global social planner allocation with the addition of a terms of trade markup, $\mu_{\gamma}=\frac{\gamma}{\gamma-1}$. Why does this happen? Mimicking the flexible wage allocation through a policy of price stability is optimal for small open economy central banks. ${ }^{10}$ In addition, fiscal authorities want to get rid of the constant markup on intermediate goods $(\mu)$ produced domestically in order to improve welfare. Thus, they choose a tax rate that cancels out the domestic monopolistic markup $\mu$. But non-cooperative fiscal authorities also want to use their monopoly power at the country level. They do not internalize the impact of charging a higher markup for their export good on the welfare of other countries, which leads them to manipulate their terms of trade. Terms of trade manipulation leads to lower welfare outcomes because every country ends up pursuing the same policy, and households must pay a terms of trade markup on each import good in the consumption basket. Even though markets are complete, the non-cooperative allocation yields lower welfare than the global social planner allocation due to the introduction of a terms of trade markup. The need for international

\footnotetext{
${ }^{10}$ In a companion paper (Dmitriev and Hoddenbagh 2012), we show that mimicking the flexible wage equilibrium is a dominant strategy for small open economy central banks. This result is robust to changes in elasticity between domestic and foreign goods, the degree of cooperation between policymakers in different countries, and the degree of financial integration across countries. Thus, the optimal policy mix for small open economies from the Mundell-Fleming Trilemma is a flexible exchange rate coupled with independent monetary policy focusing on price stability.
} 
fiscal cooperation, which would force national fiscal authorities to internalize this externality, is apparent.

Now that we've examined the complete markets equilibrium we turn our attention to the case of financial autarky. The objective function in financial autarky will be identical to the complete markets case. Domestic fiscal authorities will first choose the optimal tax rate, and then central banks will set the optimal monetary policy by choosing labor. There is a slight difference in the constraints faced by policymakers in complete markets and financial autarky. In complete markets, home consumption is a function of expected output (29b), while in autarky home consumption is a function of actual output (31b). This reflects the fact that in complete markets there is perfect risk-sharing across countries, while in autarky there is no risk-sharing.

$$
\begin{aligned}
& 1=\left(\frac{\chi \mu}{1-\tau_{i}}\right) \frac{\mathbb{E}_{t-1}\left\{N_{i t}^{1+\varphi}\right\}}{\mathbb{E}_{t-1}\left\{C_{i t}^{-\sigma} Y_{i t}^{\frac{\gamma-1}{\gamma}} C_{w, t}^{\frac{1}{\gamma}}\right\}} \\
& C_{i t}=C_{w, t}^{\frac{1}{\gamma}} Y_{i t}^{\frac{\gamma-1}{\gamma}} \\
& Y_{i t}=Z_{i t} N_{i t} \\
& C_{w t}=\left(\int_{0}^{1} Y_{i t}^{\frac{\gamma-1}{\gamma}} d i\right)^{\frac{\gamma}{\gamma-1}} .
\end{aligned}
$$

Proposition 3 Flexible Exchange Rates + Financial Autarky Non-cooperative policymakers in financial autarky will maximize (28) subject to (31a), (31b), (31c) and (31d). The solution under commitment for non-cooperative policymakers in financial autarky is:

$$
\begin{aligned}
& \mathbb{E}\left\{U_{i}\right\}=C_{i}\left(\frac{1}{1-\sigma}-\frac{1}{\mu_{\gamma}(1+\varphi)}\right) \\
& C_{i}=\left(\frac{1}{\chi \mu_{\gamma}}\right)^{\frac{1}{\sigma+\varphi}}\left(Z_{i}^{\gamma-1} Z_{w}^{\frac{1+\varphi}{\sigma+\varphi}}\right)^{\frac{1+\varphi}{1-\sigma+\gamma(\varphi+\sigma)}} \\
& N_{i}=\left(\frac{1}{\chi \mu_{\gamma}}\right)^{\frac{1}{\sigma+\varphi}}\left(Z_{i}^{\gamma-1} Z_{w}^{\frac{1+\varphi}{\sigma+\varphi}}\right)^{\frac{1-\sigma}{1-\sigma+\gamma(\varphi+\sigma)}} \\
& Y_{i}=\left(\frac{1}{\chi \mu_{\gamma}}\right)^{\frac{1}{\sigma+\varphi}}\left(Z_{i}^{\gamma-1} Z_{w}^{\frac{1+\varphi}{\sigma+\varphi}}\right)^{\frac{1-\sigma}{1-\sigma+\gamma(\varphi+\sigma)}} Z_{i} \\
& Z_{w}=\left(\int_{0}^{1} Z_{i}^{\frac{(\gamma-1)(1+\varphi)}{1-\sigma+\gamma(\sigma+\varphi)}} d i\right)^{\frac{1-\sigma+\gamma(\sigma+\varphi)}{(\gamma-1)(1+\varphi)}}
\end{aligned}
$$

The resulting equilibrium allocation replicates the flexible wage equilibrium in financial autarky with a terms of trade markup. It is optimal for non-cooperative central banks to mimic the 
flexible wage allocation. The optimal tax rate for non-cooperative fiscal authorities is $\tau_{i}=1-\frac{\mu}{\mu_{\gamma}}$.

Proof See Appendix.

As in complete markets, central banks find it optimal to mimic the flexible wage equilibrium through a policy of price stability in financial autarky. On the fiscal side, policymakers again eliminate the domestic markup $\mu$, but impose a terms of trade markup on their unique export good $\mu_{\gamma}$. Financial autarky removes cross-country consumption insurance, as households no longer have the ability to trade in international contingent claims. This can be seen most clearly in $(32 \mathrm{~b})$, where equilibrium consumption is exposed to idiosyncratic productivity, $Z_{i}$. When asset markets are complete, households do not face this idiosyncratic consumption risk.

\subsection{Currency Union}

Within a currency union, there is one central bank that sets monetary policy for the union as a whole. Countries no longer control their domestic monetary policy as they do when exchange rates are flexible. Each country maintains control over it's own fiscal policy. The objective function for non-cooperative policymakers in a currency union only accounts for fiscal authorities:

$$
\max _{\tau_{i}} \mathbb{E}_{t-1}\left\{\frac{C_{i t}^{1-\sigma}}{1-\sigma}-\chi \frac{N_{i t}^{1+\varphi}}{1+\varphi}\right\}
$$

The constraints faced by policymakers within a currency union will be identical to those faced by policymakers under flexible exchange rates, (29a) - (29d) in complete markets, and (31a) - (31d) in financial autarky, with the addition of a fifth constraint unique to currency unions. Relative to the optimization problem faced by policymakers when exchange rates are flexible, we add one constraint and subtract one FOC.

In complete markets, members of a currency union face the following constraints:

$$
\begin{aligned}
& 1=\left(\frac{\chi \mu}{1-\tau_{i}}\right) \frac{\mathbb{E}_{t-1}\left\{N_{i t}^{1+\varphi}\right\}}{\mathbb{E}_{t-1}\left\{C_{i t}^{-\sigma} Y_{i t}^{\frac{\gamma-1}{\gamma}} C_{w, t}^{\frac{1}{\gamma}}\right\}}, \\
& C_{i t}=C_{w t}^{\frac{1}{\gamma}} \mathbb{E}_{t-1}\left\{Y_{i t}^{\frac{\gamma-1}{\gamma}}\right\}, \\
& Y_{i t}=Z_{i t} N_{i t}, \\
& C_{w t}=\left(\int_{0}^{1} Y_{i t}^{\frac{\gamma-1}{\gamma}} d i\right)^{\frac{\gamma}{\gamma-1}} .
\end{aligned}
$$


We know that demand for country $i$ 's good is $Y_{i}=T O T_{i}^{-\gamma} C_{w}=\left(\frac{P_{i i}}{C P I_{i}}\right)^{-\gamma} C_{w}$ from (14) and that $P_{i i}=\frac{W_{i}}{Z_{i}}$ from (16). Plugging (16) into (14) gives:

$$
Y_{i t}=\underbrace{\left(\frac{W_{i t}}{C P I_{i t}}\right)^{-\gamma} C_{w}}_{A} Z_{i t}^{\gamma}=A Z_{i t}^{\gamma}
$$

where $A$ is a constant.

Proposition 4 Currency Union + Complete Markets Non-cooperative policymakers in a currency union will maximize (33) subject to (34a), (34b), (34c), (34d) and (34e). The solution under commitment for non-cooperative policymakers within a currency union in complete markets is:

$$
\begin{aligned}
\mathbb{E}\left\{U_{i}\right\} & =\mathbb{E}\left\{C_{i}^{1-\sigma}\right\}\left[\frac{1}{1-\sigma}-\frac{1}{\mu_{\gamma}(1+\varphi)}\right], \\
C_{i} & =C_{w}=\left(\frac{1}{\chi \mu_{\gamma}}\right)^{\frac{1}{\sigma+\varphi}}\left[\frac{\left(\int_{0}^{1} Z_{i}^{\gamma-1} d i\right)^{\frac{\gamma(1+\varphi)}{\gamma-1}}}{\int_{0}^{1} Z_{i}^{(\gamma-1)(1+\varphi)} d i}\right]^{\frac{1}{\sigma+\varphi}}, \\
N_{i} & =\left(\frac{1}{\chi \mu_{\gamma}}\right)^{\frac{1}{\sigma+\varphi}}\left[\frac{\left(\int_{0}^{1} Z_{i}^{\gamma-1} d i\right)^{\frac{\gamma(1-\sigma)}{\gamma-1}}}{\int_{0}^{1} Z_{i}^{(\gamma-1)(1+\varphi)} d i}\right]^{\frac{1}{\sigma+\varphi}} Z_{i}^{\gamma-1}, \\
Y_{i} & =\left(\frac{1}{\chi \mu_{\gamma}}\right)^{\frac{1}{\sigma+\varphi}}\left[\frac{\left(\int_{0}^{1} Z_{i}^{\gamma-1} d i\right)^{\frac{\gamma(1-\sigma)}{\gamma-1}}}{\int_{0}^{1} Z_{i}^{(\gamma-1)(1+\varphi)} d i}\right]^{\frac{1}{\sigma+\varphi}} Z_{i}^{\gamma} .
\end{aligned}
$$

The resulting equilibrium allocation does not replicate the flexible wage equilibrium. The optimal tax rate for non-cooperative fiscal authorities is $\tau_{i}=1-\frac{\mu}{\mu_{\gamma}}$.

\section{Proof See Appendix.}

Within a currency union, the inability of a union-wide central bank to alleviate asymmetric shocks across countries leads to the presence of wage rigidity in the optimal allocation. In addition, non-cooperative fiscal authorities charge a terms of trade markup, using their countrylevel monopoly power. We thus see the presence of two distortions in the equilibrium allocation: wage rigidity and a terms of trade markup. As in the flexible exchange rate allocation, there is no idiosyncratic technology risk in consumption under complete markets, so consumption will 
be equalized across countries in equilibrium. However, welfare will be lower when wages are rigid than when they are flexible, as one can notice by comparing the above allocation with the Pareto efficient allocation. ${ }^{11}$

In financial autarky, members of a currency union face the following constraints:

$$
\begin{aligned}
& 1=\left(\frac{\chi \mu}{1-\tau_{i}}\right) \frac{\mathbb{E}_{t-1}\left\{N_{i t}^{1+\varphi}\right\}}{\mathbb{E}_{t-1}\left\{C_{i t}^{-\sigma} Y_{i t}^{\frac{\gamma-1}{\gamma}} C_{w, t}^{\frac{1}{\gamma}}\right\}}, \\
& C_{i t}=C_{w t}^{\frac{1}{\gamma} Y_{i t}^{\frac{\gamma-1}{\gamma}}}, \\
& Y_{i t}=Z_{i t} N_{i t}, \\
& C_{w t}=\left(\int_{0}^{1} Y_{i t}^{\frac{\gamma-1}{\gamma}}\right)^{\frac{\gamma}{\gamma-1}} . \\
& Y_{i t}=\underbrace{\left(\frac{W_{i t}}{C P I_{i t}}\right)^{-\gamma} C_{w}}_{A} Z_{i t}^{\gamma}=A Z_{i t}^{\gamma}
\end{aligned}
$$

where $A$ is a constant.

Proposition 5 Currency Union + Financial Autarky In financial autarky, non-cooperative policymakers in a currency union will maximize (33) subject to (36a), (36c), (36b), (36d) and (36e). The optimal allocation in financial autarky given by a non-contingent policymaker in a currency union is:

$$
\begin{aligned}
\mathbb{E}\left\{U_{i}\right\} & =\mathbb{E}\left\{C_{i}^{1-\sigma}\right\}\left[\frac{1}{1-\sigma}-\frac{1}{\mu_{\gamma}(1+\varphi)}\right], \\
C_{i} & =\left(\frac{1}{\chi \mu_{\gamma}}\right)^{\frac{1}{\sigma+\varphi}}\left[\frac{\left(\int_{0}^{1} Z_{i}^{(\gamma-1)(1-\sigma)} d i\right)\left(\int_{0}^{1} Z_{i}^{\gamma-1} d i\right)^{\frac{1+\varphi}{\gamma-1}}}{\int_{0}^{1} Z_{i}^{(\gamma-1)(1+\varphi)} d i}\right]^{\frac{1}{\sigma+\varphi}} Z_{i}^{\gamma-1}, \\
N_{i} & =\left(\frac{1}{\chi \mu_{\gamma}}\right)^{\frac{1}{\sigma+\varphi}}\left[\frac{\left(\int_{0}^{1} Z_{i}^{(\gamma-1)(1-\sigma)} d i\right)\left(\int_{0}^{1} Z_{i}^{\gamma-1} d i\right)^{\frac{1-\sigma}{\gamma-1}}}{\int_{0}^{1} Z_{i}^{(\gamma-1)(1+\varphi)} d i}\right]_{i}^{\frac{1}{\sigma+\varphi}} Z_{i}^{\gamma-1}, \\
Y_{i} & =\left(\frac{1}{\chi \mu_{\gamma}}\right)^{\frac{1}{\sigma+\varphi}}\left[\frac{\left(\int_{0}^{1} Z_{i}^{(\gamma-1)(1-\sigma)} d i\right)\left(\int_{0}^{1} Z_{i}^{\gamma-1} d i\right)^{\frac{1-\sigma}{\gamma-1}}}{\int_{0}^{1} Z_{i}^{(\gamma-1)(1+\varphi)} d i}\right]_{i}^{\frac{1}{\sigma+\varphi}}
\end{aligned}
$$

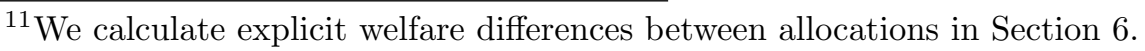


The resulting equilibrium allocation does not replicate the flexible wage allocation. The optimal tax rate for non-cooperative fiscal authorities is $\tau_{i}=1-\frac{\mu}{\mu_{\gamma}}$.

Proof See Appendix.

Members of a currency union, facing non-cooperative policymakers in other countries, and unable to trade contingent claims across borders, will be subject to three distortions: wage rigidity resulting from the absence of country-specific monetary policy; TOT markups, imposed by non-cooperative fiscal authorities in other countries; and idiosyncratic consumption risk, caused by lack of access to international financial markets. All three distortions decrease welfare. The potential for cooperative measures to ameliorate these distortions will be discussed in detail in Section 5 below.

\subsection{A Note On Contingent Fiscal Policy}

In our analysis of non-cooperative policy within a currency union, the lack of country-specific monetary policy introduces wage rigidity into the optimal allocation. The union-wide central bank, with only one policy instrument at its disposal, cannot mimic the flexible wage equilibrium in each country when shocks are asymmetric. To do so would require the same number of policy instruments as shocks. As union-wide monetary policy cannot is unable to deal effectively with wage rigidity, is there a role for country-specific fiscal policy to do so? Yes, but this requires contingent fiscal policy at the national level.

Up to this point, we have assumed that fiscal policy is non-contingent, so that fiscal authorities can only set constant tax rates. If we relax this assumption and allow for contingent fiscal policy that can adjust tax rates over the business cycle, the objective function for policymakers is

$$
\max _{N_{i t}} \max _{\tau_{i t}} \mathbb{E}_{t-1}\left\{\frac{C_{i t}^{1-\sigma}}{1-\sigma}-\chi \frac{N_{i t}^{1+\varphi}}{1+\varphi}\right\},
$$

when exchange rates are flexible, and

$$
\max _{\tau_{i t}} \mathbb{E}_{t-1}\left\{\frac{C_{i t}^{1-\sigma}}{1-\sigma}-\chi \frac{N_{i t}^{1+\varphi}}{1+\varphi}\right\}
$$

within a currency union.

Proposition 6 Contingent Fiscal Policy When exchange rates are flexible, national central banks will mimic the flexible wage allocation and a constant labor tax rate will be optimal for both contingent and non-contingent fiscal policymakers. Within a currency union the unionwide central bank, with only one policy instrument, cannot mimic the flexible wage equilbrium 
in each country due to asymmetric shocks. Contingent national fiscal policy can fill the void, setting domestic tax rates in each period to remove domestic wage rigidity and mimic the flexible wage equilibrium. Formally, contingent non-cooperative policymakers will maximize (38) when exchange rates are flexible, or (39) within a currency union, subject to (29a) - (29d) in complete markets and (31a) - (31d) in autarky. The optimal allocations under flexible exchange rates and within a currency union will exactly coincide with (30a) - (30e) in complete markets and (32a) - (32e) in autarky. The resulting equilibrium allocations replicate the flexible wage allocations with a terms of trade markup.

Contingent fiscal policy is redundant when exchange rates are flexible because national central banks adjust monetary policy over the business cycle to counteract wage rigidity. However, within a currency union the union-wide central bank is unable to counteract domestic wage rigidity in the presence of asymmetric shocks. Contingent fiscal policy thus has a role to play in eliminating wage rigidity at the national level. Importantly, international policy cooperation is not necessary to deal with this distortion. One already begins to see that fiscal policy is more important within a currency union than outside of one. For the remainder of the paper, we will assume that fiscal policy is non-contingent. However, keep in mind that contingent fiscal policy eliminates any differences between flexible exchange rates and currency unions.

\section{Cooperative Policy}

In the previous section we solved for the Nash equilibrium allocations resulting from no international policy cooperation of any kind. Policymakers focused only on maximizing the welfare of their domestic households without internalizing the impact of their policy decisions on other countries. The non-cooperative allocations featured three distortions: TOT markups, wage rigidity and lack of access to international financial markets. Proposition 6 proved that contingent fiscal policy is sufficient to eliminate wage rigidity within a currency union, while domestic monetary policy is sufficient to eliminate wage rigidity outside of a currency union. In both cases, policy cooperation is unnecessary. In this section, we will show that the ill effects of the remaining two distortions can be remedied with appropriate international policy cooperation. The mechanisms necessary for such cooperation, both outside of and within currency unions, will be described in detail.

International policy cooperation has many possible dimensions, but we focus here on three: monetary cooperation between central banks, and two types of fiscal union - tax unions and transfer unions. Figure 2 below describes the possible "coalitions" between a home and 
foreign country. Coalitions simply refer to any mixture of policy cooperation. Each arrow denotes cooperation: as such, we can have complete cooperation (all arrows), no cooperation (no arrows), or any set of cooperation in between. Remember that monetary policy cooperation is only possible outside of a currency union, while tax and transfer unions are possible both outside of and within a currency union.

\section{Figure 2}

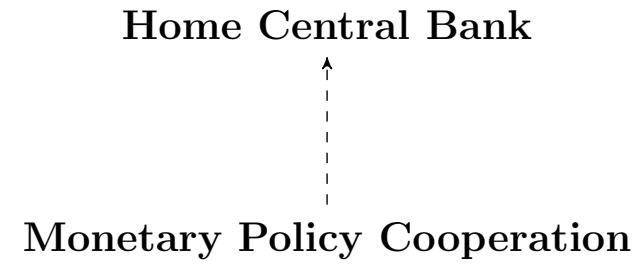

Foreign Central Bank
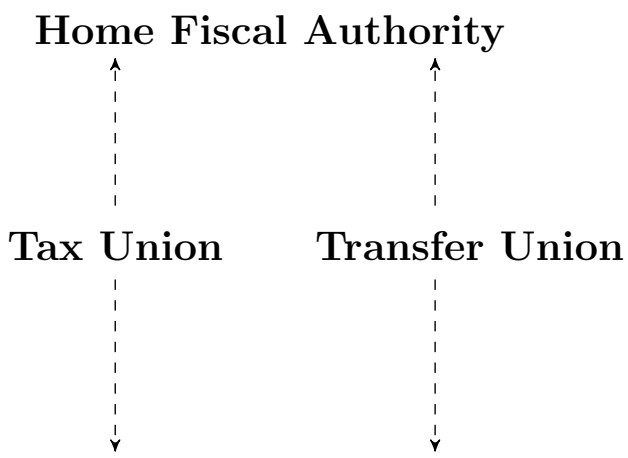

Foreign Fiscal Authority

As outlined in the introduction, we break down the concept of a fiscal union into two separate components, tax unions and transfer unions, for the sake of clarity. A tax union refers to crosscountry cooperation in the setting of labor tax rates. The tax union can be viewed as a simple cross-country agreement on tax rates between domestic fiscal authorities, or a mandatory tax rate imposed by a supranational tax authority. Tax unions eliminate the incentive to charge a terms of trade markup on the export of a country's unique good. A transfer union provides cross-country transfers that maximize the welfare of all $i$ countries in the model. Transfers can be agreed to by national fiscal authorities or imposed by a supranational fiscal authority akin to the federal government in the United States for example. Transfer unions enable perfect cross-country consumption insurance but are redundant when the elasticity of substitution between domestic and foreign products is equal to one, or when international asset markets are complete. Transfer unions improve welfare greatly when substitutability is different from one and markets are no longer complete.

As we've already established, each country outside of a currency union has its own central bank. Does cooperation between central banks improve welfare? In a companion paper (Dmitriev and Hoddenbagh (2013)), we show that monetary cooperation yields no welfare gains. Non-cooperative and cooperative Nash equilibria exactly coincide in the continuum framework because each small open economy has zero weight in the consumption basket of other countries. As such, strategic interactions do not occur, markups are constant, and national central 
banks always find it optimal to mimic the flexible wage equilibrium through a policy of price stability. More formally, price stability is the dominant strategy in both cooperative and noncooperative Nash equilibria when exchange rates are flexible. Monetary cooperation is not possible for countries within a currency union, as there is only one central bank.

Although not shown in Figure 2, within country cooperation between the domestic fiscal and monetary authority is also possible. As a robustness check, we computed the optimal allocations under this scenario, and found that the presence or absence of cooperation between the domestic fiscal and monetary authority had no impact on the results. For the remainder of the paper, we assume that the domestic fiscal and monetary authority act independently of one another.

The objective functions for all possible combinations of policy cooperation are below. ${ }^{12}$

$$
\begin{aligned}
& \max _{\forall \tau_{i}} \int_{0}^{1}\left[\max _{N_{i t}} \mathbb{E}_{t-1}\left\{\frac{C_{i t}^{1-\sigma}}{1-\sigma}-\chi \frac{N_{i t}^{1+\varphi}}{1+\varphi}\right\}\right] d i \\
& \max _{\forall \tau_{i}} \int_{0}^{1}\left[\mathbb{E}_{t-1}\left\{\frac{C_{i t}^{1-\sigma}}{1-\sigma}-\chi \frac{N_{i t}^{1+\varphi}}{1+\varphi}\right\}\right] d i
\end{aligned}
$$

(40a) and (40b) refer to a tax union outside of and within a currency union, respectively. Here, the fiscal authorities in each country agree on the optimal labor tax rate to set.

$$
\begin{aligned}
& \max _{\forall \mathcal{T}_{i t}} \int_{0}^{1}\left[\max _{N_{i t}} \max _{\tau_{i}} \mathbb{E}_{t-1}\left\{\frac{C_{i t}^{1-\sigma}}{1-\sigma}-\chi \frac{N_{i t}^{1+\varphi}}{1+\varphi}\right\}\right] d i \\
& \max _{\forall \mathcal{T}_{i t}} \int_{0}^{1}\left[\max _{\tau_{i}} \mathbb{E}_{t-1}\left\{\frac{C_{i t}^{1-\sigma}}{1-\sigma}-\chi \frac{N_{i t}^{1+\varphi}}{1+\varphi}\right\}\right] d i
\end{aligned}
$$

(40c) and (40d) refer to a transfer union outside of and within a currency union, respectively. Here, a supranational (or federal) fiscal body optimally chooses cross-country transfers in order to maximize union-wide welfare.

$$
\begin{aligned}
& \max _{\forall \tau_{i}, \mathcal{T}_{i t}} \int_{0}^{1}\left[\max _{N_{i t}} \mathbb{E}_{t-1}\left\{\frac{C_{i t}^{1-\sigma}}{1-\sigma}-\chi \frac{N_{i t}^{1+\varphi}}{1+\varphi}\right\}\right] d i \\
& \max _{\forall \tau_{i}, \mathcal{T}_{i t}} \int_{0}^{1}\left[\mathbb{E}_{t-1}\left\{\frac{C_{i t}^{1-\sigma}}{1-\sigma}-\chi \frac{N_{i t}^{1+\varphi}}{1+\varphi}\right\}\right] d i
\end{aligned}
$$

Finally, (40e) and (40f) refer to a tax and transfer union outside of and within a currency union, respectively. Here, countries not only agree on labor tax rates, but also agree to send

\footnotetext{
${ }^{12}$ We ignore monetary cooperation here and focus only on non-cooperative central banks. As we explained above, the Nash equilibrium is unaffected by the presence of monetary cooperation. For an in-depth look at monetary cooperation among a continuum of small open economies, see Dmitriev and Hoddenbagh (2013).
} 
contingent cash transfers across countries.

Proposition 7 Tax Unions Policymakers in a tax union will internalize the impact of their labor tax rate on all union members. As a result, a tax union will remove the incentive for policymakers to manipulate their terms of trade. The optimal tax rate in a tax union is $\tau_{i}=$ $1-\mu$, which will remove the markup on domestic production in each country, $\mu$, while preventing the imposition of a terms of trade markup on exports, $\mu_{\gamma}$, from all equilibrium allocations. Note that a tax union can be formed independently of a transfer or currency union.

Proof See Appendix.

As we discussed in the introduction, the importance of a tax union increases as export goods become less substitutabile because countries gain monopoly power. The distortion resulting from the terms of trade markup, $\mu_{\gamma}$, rises as substitutability decreases.

Now we turn our attention to a transfer union. Members of a transfer union agree to send contingent cash transfers across countries in order to insure against idiosyncratic consumption risk. The economic benefits of a transfer union are identical to those deriving from internationally complete asset markets: namely, perfect cross-country risk-sharing. As such, when international asset markets are complete, there is no need for a transfer union. However, in financial autarky a transfer union will enable cross-country risk-sharing in spite of the inability to trade in contingent claims internationally.

In complete markets the presence of cross-country transfers will alter the goods market clearing constraint, so that $(29 b)$ is replaced by the following two conditions:

$$
\begin{gathered}
C_{i t}=C_{w t}^{\frac{1}{\gamma}} \mathbb{E}_{t-1}\left\{Y_{i t}^{\frac{\gamma-1}{\gamma}}\right\}+\mathcal{T}_{i t}, \\
\text { where } \int_{0}^{1} \mathcal{T}_{i t} d i=0
\end{gathered}
$$

In financial autarky the presence of cross-country transfers will alter the goods market clearing constraint, so that (31b) is replaced by the following two conditions:

$$
\begin{gathered}
C_{i t}=C_{w t}^{\frac{1}{\gamma}} Y_{i t}^{\frac{\gamma-1}{\gamma}}+\mathcal{T}_{i t}, \\
\text { where } \int_{0}^{1} \mathcal{T}_{i t} d i=0 .
\end{gathered}
$$

Proposition 8 Transfer Unions Policymakers in a transfer union agree to send contingent cash transfers across countries in order to insure against idiosyncratic consumption risk. The 
equilibrium allocation within a transfer union will be identical with the equilibrium allocation under complete markets. As a result, transfer unions are redundant when international asset markets are complete or when substitutability is one, but yield large welfare gains in financial autarky. Note that a transfer union can be formed independently of a tax or currency union.

\section{Proof See Appendix.}

We now see that the path to the Pareto optimal allocation is paved with the following ingredients: (1) internationally complete asset markets or a transfer union; (2) independent monetary policy outside of a currency union or contingent fiscal policy within a currency union; and (3) a tax union. (1) provides cross-country risk-sharing, (2) eliminates wage rigidity, and (3) prevents terms of trade manipulation. Any combination of (1), (2) and (3), for example a tax and transfer union whose members control their own monetary policy outside of a currency union, will yield the Pareto optimal allocation. However, the relative importance of these ingredients is determined by the degree of substitutability between domestic and foreign products. We will prove this explicitly in Section 6 below.

\section{Welfare Analysis}

In this section we analyze the welfare gains resulting from the elimination of three distortions: terms of trade manipulation (eliminated via a tax union), a lack of risk-sharing (eliminated via financial integration or the formation of transfer union), and wage rigidity (eliminated via flexible exchange rates or contingent fiscal policy within a currency union). To explicitly calculate welfare, technology is assumed to be log-normally distributed in all countries: $\log \left(Z_{i}\right) \sim N\left(0, \sigma_{Z}^{2}\right)$. The assumption of independence across time and across countries for technology remains.

We begin our welfare analysis by focusing on the impact of a tax union. Below we compare the welfare of a country outside of a tax union (denoted by tax) with the welfare of a country inside a tax union (denoted by notax), assuming that the two countries are identical in all other respects. ${ }^{13}$

$$
\log \mathbb{E}\left\{U_{\text {tax }}\right\}-\mathbb{E}\left\{U_{\text {notax }}\right\}=\left(\frac{1-\sigma}{\sigma+\varphi}\right) \log \mu_{\gamma}=\left(\frac{1-\sigma}{\sigma+\varphi}\right) \log \left(\frac{\gamma}{\gamma-1}\right)
$$

As goods become closer substitutes, country level monopoly power decreases and the distortionary impact of the terms of trade markup decreases. From this it is immediately clear that

\footnotetext{
${ }^{13}$ That is, both countries are subject to the same distortions in all other respects, and differ only in the fact that one country is a member of a tax union and one country is not.
} 
the welfare gains from a tax union are decreasing in $\gamma$, the degree of substitutability between products across countries. In the limit, as $\gamma \rightarrow \infty$ and goods become perfect substitutes, a tax union will have zero impact on welfare. On the other hand, as $\gamma \rightarrow 1$, the welfare benefits of a tax union become quite large.

Now, let us calculate the welfare gains achieved through improved risk-sharing as well as through the elimination of wage rigidity. We ignore the impact of a tax union, which serves to remove the constant terms of trade markup $\mu_{\gamma}$, because this constant term will drop out in welfare comparisons between different allocations. We will concentrate on the following cases: perfect consumption insurance across countries via financial integration or a transfer union, no consumption insurance across countries resulting from financial autarky and no transfer union, both outside of and within a currency union. Below, we compare the expected utility for flexible exchange rate regimes (or contingent fiscal policy within a currency union) and currency unions under complete markets and financial autarky. Allocations that eliminate wage rigidity are denoted by flex, while those that do not are denoted by fixed. Similarly, allocations with complete international risk-sharing are denoted by complete, while autarky allocations with no risk-sharing are denoted by autarky.

$$
\begin{aligned}
\mathbb{E}\left\{U_{i}\right\} & =\mathbb{E}\left\{C_{i}^{1-\sigma}\right\}\left[\frac{1}{1-\sigma}-\frac{1-\tau_{i}}{\mu(1+\varphi)}\right] \\
C_{\text {flex,complete }} & =\left(\frac{1-\tau_{i}}{\chi \mu}\right)^{\frac{1}{\sigma+\varphi}}\left(\int_{0}^{1} Z_{i}^{\frac{(\gamma-1)(1+\varphi)}{1+\gamma \varphi}} d i\right)^{\frac{1+\gamma \varphi}{(\gamma-1)(\sigma+\varphi)}} \\
C_{\text {fixed,complete }} & =\left(\frac{1-\tau_{i}}{\chi \mu}\right)^{\frac{1}{\sigma+\varphi}}\left[\frac{\left(\int_{0}^{1} Z_{i}^{\gamma-1} d i\right)^{\frac{\gamma(1+\varphi)}{\gamma-1}}}{\int_{0}^{1} Z_{i}^{(\gamma-1)(1+\varphi)} d i}\right]^{\frac{1}{\sigma+\varphi}} \\
C_{\text {flex,autarky }} & =\left(\frac{1-\tau_{i}}{\chi \mu}\right)^{\frac{1}{\sigma+\varphi}}\left(Z_{i}^{\frac{(\gamma-1)(1+\varphi)}{1-\sigma+\gamma(\sigma+\varphi)}}\right)\left(\int_{0}^{1} Z_{i}^{\frac{(\gamma-1)(1+\varphi)}{1-\sigma+\gamma(\sigma+\varphi)}} d i\right)^{\frac{(1+\varphi)}{(\gamma-1)(\sigma+\varphi)}} \\
C_{\text {fixed,autarky }} & =\left(\frac{1-\tau_{i}}{\chi \mu}\right)^{\frac{1}{\sigma+\varphi}}\left[\frac{\left(\int_{0}^{1} Z_{i}^{(\gamma-1)(1-\sigma)} d i\right)\left(\int_{0}^{1} Z_{i}^{\gamma-1} d i\right)^{\frac{1+\varphi}{\gamma-1}}}{\int_{0}^{1} Z_{i}^{(\gamma-1)(1+\varphi)} d i}\right]_{i}^{\frac{1}{\sigma+\varphi}} Z_{i}^{\gamma-1}
\end{aligned}
$$

As we've discussed multiple times now, risk-sharing is complete when the substitutability between foreign and domestic products is unitary $(\gamma=1)$, regardless of financial market structure. 
You can see this by looking at the exponent for $Z_{i}$ in the autarky allocations. When substitutability equals one, idiosyncratic consumption risk disappears from the equilibrium allocation in autarky, so that:

$$
C_{\text {flex,complete } \mid \gamma=1}=C_{\text {fixed,complete } \mid \gamma=1}=C_{\text {flex,autarky } \mid \gamma=1}=C_{\text {fixed,autarky } \mid \gamma=1}=\left(\frac{1-\tau_{i}}{\chi \mu}\right)^{\frac{1}{\sigma+\varphi}}
$$

In what follows, we ignore the constant terms and focus only on the exponents of $Z$. Details on how to compute the welfare measures below are contained in the Appendix.

$$
\begin{aligned}
\log \mathbb{E}\left\{U_{\text {flex,complete }}\right\} & =\frac{(\gamma-1)(1+\varphi)^{2}(1-\sigma)}{(1+\gamma \varphi)(\sigma+\varphi)} \sigma_{Z}^{2} \\
\log \mathbb{E}\left\{U_{\text {fixed,complete }}\right\} & =\frac{(\gamma-1)(1+\varphi)(1-\sigma)(1+\varphi-\gamma \varphi)}{(\sigma+\varphi)} \sigma_{Z}^{2} \\
\log \mathbb{E}\left\{U_{\text {flex,autarky }}\right\} & =\frac{(\gamma-1)(1+\varphi)^{2}(1-\sigma)}{(\sigma+\varphi)[1-\sigma+\gamma(\sigma+\varphi)]} \sigma_{Z}^{2} \\
\log \mathbb{E}\left\{U_{\text {fixed,autarky }}\right\} & =\left[\frac{(\gamma-1)(1-\sigma)(1+\varphi)}{(\sigma+\varphi)}-\gamma+1\right] \sigma_{Z}^{2}
\end{aligned}
$$

Using these expected utilities, and the fact that any constant terms will cancel out when subtracted from each other, we calculate the welfare differences for four scenarios: (1) complete markets vs. autarky for flexible exchange rates; (2) complete markets vs. autarky for fixed exchange rates; (3) flexible vs. fixed exchange rates for complete markets; and (4) flexible vs. fixed exchange rates for autarky.

$$
\begin{aligned}
\log \mathbb{E}\left\{U_{\text {flex,complete }}\right\}-\log \mathbb{E}\left\{U_{\text {flex,autarky }}\right\} & =\frac{\sigma(\gamma-1)^{2}(1-\sigma)(1+\varphi)^{2}}{(\sigma+\varphi)(1+\gamma \varphi)[1-\sigma+\gamma(\sigma+\varphi)} \sigma_{Z}^{2} \\
\log \mathbb{E}\left\{U_{\text {fixed,complete }}\right\}-\log \mathbb{E}\left\{U_{\text {fixed,autarky }}\right\} & =\frac{\sigma(\gamma-1)^{2}(1-\sigma)(1+\varphi)}{\sigma+\varphi} \sigma_{Z}^{2} \\
\log \mathbb{E}\left\{U_{\text {flex,complete }}\right\}-\log \mathbb{E}\left\{U_{\text {fixed,complete }}\right\} & =\frac{\gamma \varphi^{2}(\gamma-1)^{2}(1-\sigma)(1+\varphi)}{(1+\gamma \varphi)(\sigma+\varphi)} \sigma_{Z}^{2} \\
\log \mathbb{E}\left\{U_{\text {flex,autarky }}\right\}-\log \mathbb{E}\left\{U_{\text {fixed,autarky }}\right\} & =\frac{(\gamma-1)^{2}(1-\sigma)(1+\varphi)[\gamma(\sigma+\varphi)-\sigma]}{1+\gamma(\sigma+\varphi)-\sigma} \sigma_{Z}^{2}
\end{aligned}
$$

Note that increased risk-sharing always has positive (or neutral) welfare consequences, while moving from fixed to flexible exchange rates (or non-contingent to contingent fiscal policy) also has positive or neutral effects on welfare. When comparing welfare across different scenarios, it is important to keep in mind that as risk-aversion decreases, (i.e. as $\sigma \rightarrow 1$ ), the welfare differences expressed in logarithms also decrease but the absolute values of utility increase. In 
other words, when risk version is low, the welfare differences shown in (45a) - (45d) will shrink, but this does not mean that the welfare differences are decreasing in absolute value.

In the special case of $\gamma=1$ the expected utility for all policy coalitions is identical. Under this special assumption, there is no difference in welfare between a fixed and flexible exchange rate, nor is there any benefit from improved risk-sharing across countries. Equations (45a) - (45d) thus demonstrate the restrictive nature of assuming unitary elasticity, as in Corsetti and Pesenti (2001, 2005), Obstfeld and Rogoff (2000, 2002), and Farhi and Werning (2012). In particular, as we've mentioned above, unitary elasticity of substitution between home and foreign goods: (i) leads to complete risk-sharing, eliminating any difference between allocations in complete markets and financial autarky and (ii) eliminates wage rigidities, removing the difference between allocations under flexible exchange rates and within a currency union as well as between non-contingent and contingent domestic fiscal policy in a currency union. In both cases, risk-sharing and the elimination of nominal rigidities occur via movements in the terms of trade. ${ }^{14}$ This explains why Obstfeld and Rogoff and others found such small gains from cooperation: when elasticity is unitary, there are simply no gains from cooperation available as movements in the terms of trade fill the role of cross-country risk-sharing and negate the influence of nominal rigidities.

Another interesting welfare comparison concerns the gains from financial integration outside of and within currency unions. Using (45a) - (45d), one can easily show that

$$
\log \mathbb{E}\left\{U_{\text {flex,complete }}\right\}-\log \mathbb{E}\left\{U_{\text {flex,autarky }}\right\} \leq \log \mathbb{E}\left\{U_{\text {fixed,complete }}\right\}-\log \mathbb{E}\left\{U_{\text {fixed,autarky }}\right\},
$$

$$
\log \mathbb{E}\left\{U_{\text {flex,complete }}\right\}-\log \mathbb{E}\left\{U_{\text {fixed,complete }}\right\} \leq \log \mathbb{E}\left\{U_{\text {flex,autarky }}\right\}-\log \mathbb{E}\left\{U_{\text {fixed,autarky }}\right\} .
$$

Equation (46a) shows that the gains from improved risk-sharing brought on by deeper financial integration or a transfer union are higher within a currency union than outside of one. Equation (46b) shows that the losses resulting from wage rigidity are lower when cross-country risksharing is complete.

One of the arguments in support of a currency union, advanced by Mundell (1973) among others, is that the formation of such a union will lead to deeper financial integration and improve cross-country risk sharing. Using this logic, we conduct a thought experiment on the potential

\footnotetext{
${ }^{14}$ This occurs in spite of the fact that Corsetti and Pesenti have riskless bonds in their model, implying an incomplete markets setup. Given the assumption of unitary elasticity, there is already perfect risk-sharing.
} 
benefits of a currency union. We first take a country outside a currency union and assume it is in financial autarky. Then we take a member of a currency union and assume that it has access to internationally complete asset markets so that it faces no idiosyncratic consumption risk. The welfare of these two countries is compared directly, offering us an explicit calculation of the benefits of a currency union. Is a country better off with a flexible exchange rate and no risk-sharing, or in a currency union with perfect risk-sharing? The answer will depend on the degree of risk aversion as well as the degree of substitutability between domestic and foreign products. A country with a flexible exchange rate and no risk-sharing is better off than a country in a currency union with perfect risk-sharing whenever

$$
\frac{\sigma(\gamma-1)^{2}(1+\varphi)}{[1-\sigma+\gamma(\sigma+\varphi)]} \leq \gamma \varphi^{2}(\gamma-1)^{2}
$$

which can be rewritten in quadratic form as

$$
\gamma^{2}(\sigma+\varphi)+\gamma(1-\sigma)-\frac{\sigma(1+\varphi)}{\varphi^{2}} \geq 0
$$

The solution to this quadratic equation is:

$$
\gamma \geq \frac{(\sigma-1)+\sqrt{(1-\sigma)^{2}+\frac{4 \sigma(1+\varphi)(\sigma+\varphi)}{\varphi^{2}}}}{2(\sigma+\varphi)}
$$

When $\gamma$ is greater than or equal to the term on the right hand side of (49), a country will be better off outside of a currency union in financial autarky than as a member of a currency union in complete markets.

First of all, notice that the relative importance of risk-sharing increases as the degree of risk aversion $(\sigma)$ increases. For low values of risk aversion, households will prefer to keep a flexible exchange rate even if it means they have no access to international financial markets. As households become more risk averse, they will prefer to join a currency union with full risk-sharing. Note that we are estimating an upper bound on the benefits of a currency union by assuming that membership moves a country from financial autarky to complete markets. Even in this extreme case, it is not clear that joining a currency union is worth the loss of independent monetary policy.

Secondly, notice that as the degree of substitutability $(\gamma)$ increases, the losses from financial autarky fall relative to the gains from independent monetary policy. What causes this? Assume country $i$ is hit with a negative productivity shock. If country $i$ is a member of a currency union, 
wage rigidity will force its producers to charge a higher price. With a flexible exchange rate, the higher domestic price would be offset by a depreciated currency, but in a currency union this effect is absent. Given the higher price, consumers in country $i$ and in other countries will switch to cheaper substitutes. If the elasticity of substitution is very high, demand for country $i^{\prime}$ s good will collapse, and country $i$ will produce almost nothing. If markets within the currency union are complete or a transfer union is in place, consumption must be equal across countries. However only a few countries will produce any output, and households in those few countries will have to work long hours to supply goods for the whole currency union. As a result, average consumption and welfare will fall. This effect is exacerbated as goods become closer substitutes. In the limit, when goods are perfect substitutes $(\gamma=\infty)$ and shocks are asymmetric, only one country in the currency union will produce any output, and consumption and welfare will equal zero for all countries in the union. Remember from Proposition 6 that contingent domestic fiscal policy within a currency union can completely alleviate the negative impact of wage rigidity described here.

When substitutability is close to one, the welfare losses from wage rigidity and the gains from risk-sharing go to zero. Terms of trade movements will provide risk-sharing and insulate economies from the negative impact of asymmetric productivity shocks and nominal rigidities. In this case, a country will be indifferent between remaining outside a currency union in financial autarky and joining a currency union with full risk-sharing.

In reality of course, membership in a currency union does not guarantee perfect risk-sharing through access to complete markets. Nor does lack of membership in a currency union prevent countries from accessing international financial markets. Whether countries enjoy some degree of cross-border risk-sharing seems to be largely unrelated to their membership in a currency union, although it is true that the introduction of the euro led to an increase in cross-border lending within the euro area, as well as a convergence of borrowing rates within the union.

In the figure below, we estimate the upper bound of the benefits from joining a currency union and show that they are insufficient to overcome the losses from wage rigidity. We set the risk aversion parameter, $\sigma$, at 10 . While this may seem high relative to standard calibrations, we are in fact biasing the welfare results in favor of the currency union-complete markets allocation and against the flexible wage-autarky allocation due to the high degree of risk aversion. The figure below thus overemphasizes the benefits of joining a currency union that guarantees access to complete markets relative to maintaining independent monetary policy outside of such a union in financial autarky. Even so, we still find that the benefits of joining a currency union are 
outweighed by the loss of independent monetary policy for $\gamma>2.7$, which is well within the range of plausible micro estimates for the degree of substitutability.

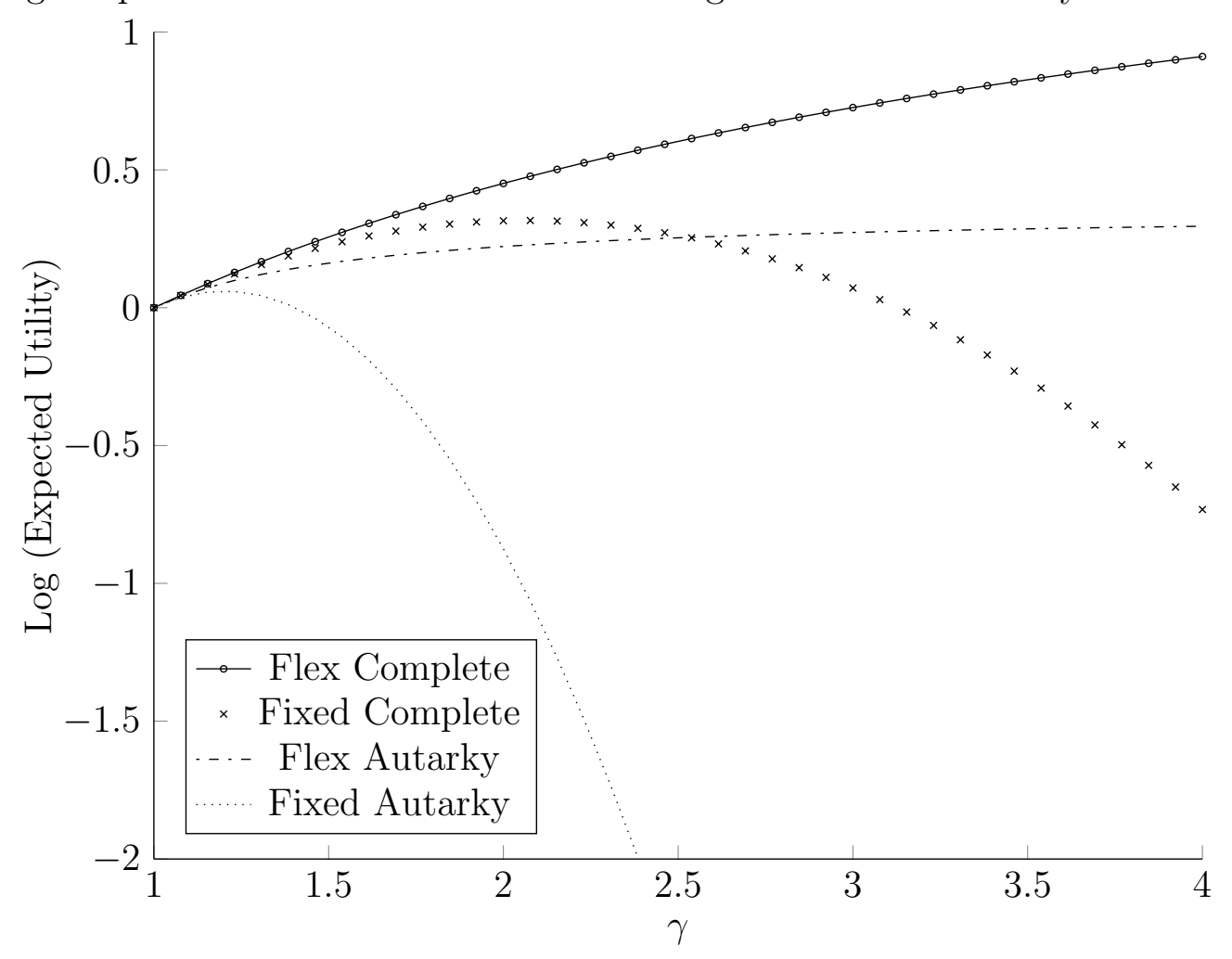

\section{Conclusion}

In this paper we derive a global closed-form solution for an open economy model with nominal rigidities. Using this global closed-form solution, we study the benefits of a fiscal union within a currency union in complete markets and financial autarky, for varying degrees of substitutability between domestic and foreign products. Differently from the standard modeling framework in the literature, we assume a continuum of small open economies interacting in general equilibrium, rather than two large open economies of equal size. Each country exports all of its production and imports varieties from all other countries to aggregate into a final consumption basket. This setup allows us to examine the optimal structure of a fiscal union and calculate the gains from cooperation among national policymakers for an incredibly broad set of scenarios.

We show that the optimal design of a fiscal union depends crucially on the degree of substitutability between domestic and foreign products. When substitutability is low (around one), risk-sharing occurs naturally via terms of trade movements. In this case, a transfer union is redundant, as are complete markets. However, terms of trade externalities will be large, and optimal policy will prevent terms of trade manipulation via a tax union. When substitutability 
is high (above one), risk-sharing no longer occurs naturally via terms of trade movements. If financial markets do not provide complete risk-sharing across countries, there is a role for a transfer union to insure against idiosyncratic shocks. The relative importance of a transfer union increases as goods become more substitutable. On the other hand, terms of trade externalities, and hence tax unions, become much less important as substitutability increases due to a loss of monopoly power at the country level. Finally, we show that even if a fiscal union fails to materialize, contingent domestic fiscal policy can eliminate nominal rigidities and yield large welfare gains when goods are close substitutes. 


\section{References}

[1] Roel M.W.J. Beetsma and Henrik Jensen. Monetary and fiscal policy interactions in a micro-founded model of a monetary union. Journal of International Economics, 67(2):320352, December 2005.

[2] Gianluca Benigno and Bianca De Paoli. On the international dimension of fiscal policy. Journal of Money, Credit and Banking, 42(8):1523-1542, December 2010.

[3] Laura Bottazzi and Paolo Manasse. Asymmetric information and monetary policy in common currency areas. Journal of Money, Credit and Banking, 37(4):603-21, August 2005.

[4] Matthew B. Canzoneri and Dale W. Henderson. Monetary Policy in Interdependent Economies: A Game-Theoretic Approach, volume 1 of MIT Press Books. The MIT Press, 1991.

[5] Harold L. Cole and Maurice Obstfeld. Commodity trade and international risk sharing : How much do financial markets matter? Journal of Monetary Economics, 28(1):3-24, August 1991.

[6] Giancarlo Corsetti and Paolo Pesenti. Welfare and macroeconomic interdependence. The Quarterly Journal of Economics, 116(2):421-445, May 2001.

[7] Giancarlo Corsetti and Paolo Pesenti. International dimensions of optimal monetary policy. Journal of Monetary Economics, 52(2):281-305, March 2005.

[8] Michael B. Devereux and Charles Engel. Monetary policy in the open economy revisited: Price setting and exchange-rate flexibility. Review of Economic Studies, 70(4):765-783, October 2003.

[9] Mikhail Dmitriev and Jonathan Hoddenbagh. Price stability in small open economies. 2013.

[10] Barry Eichengreen and Fabio Ghironi. Transatlantic trade-offs in the age of balanced budgets and european monetary union. Open Economies Review, 13(4):381-411, October 2002. 
[11] Robert Feenstra, Maurice Obstfeld, and Katheryn Russ. In search of the armington elasticity. 2010.

[12] Andrea Ferrero. Fiscal and monetary rules for a currency union. Journal of International Economics, 77(1):1-10, February 2009.

[13] Jordi Gali and Tommaso Monacelli. Optimal monetary and fiscal policy in a currency union. Journal of International Economics, 76(1):116-132, September 2008.

[14] Jordi Galí and Tommaso Monacelli. Monetary policy and exchange rate volatility in a small open economy. Review of Economic Studies, 72(3):707-734, 072005.

[15] Jean Imbs and Isabelle Mejean. Elasticity optimism. CEPR Discussion Papers 7177, C.E.P.R. Discussion Papers, February 2009.

[16] Huiwen Lai and Daniel Trefler. The gains from trade with monopolistic competition: Specification, estimation, and mis-specification. NBER Working Papers 9169, National Bureau of Economic Research, Inc, September 2002.

[17] Maurice Obstfeld and Kenneth Rogoff. New directions for stochastic open economy models. Journal of International Economics, 50(1):117-153, February 2000.

[18] Maurice Obstfeld and Kenneth Rogoff. Global implications of self-oriented national monetary rules. The Quarterly Journal of Economics, 117(2):503-535, May 2002.

[19] Ivan Werning and Emmanuel Farhi. Fiscal unions. NBER Working Papers 18280, National Bureau of Economic Research, Inc, August 2012. 


\section{Appendix}

\section{Risk-sharing}

The household in country $i$ will maximize lifetime utility (4), subject to the following budget constraint and transversality condition:

$$
\begin{array}{r}
C_{i}\left(s_{t}\right) P_{i}\left(s_{t}\right)=W_{i}\left(s_{t}\right) N_{i}\left(s_{t}\right)+\int_{0}^{1} \mathcal{E}_{i j t} B_{i j}\left(s_{t}\right) d j \\
\sum_{t=1}^{\infty} \sum_{s_{t}} \int_{0}^{1} q_{j}\left(s_{t}\right) B_{i j}\left(s_{t}\right) d j=0 .
\end{array}
$$

$B_{i j}\left(s_{t}\right)$ denotes the state-contingent bond that pays in currency $j$ in state $s_{t} ; q_{j}\left(s_{t}\right)$ is the price of that bond in period 0 (when all trading occurs), $q_{j}\left(s_{t}\right)$ is arbitrary up to a constant. Household in period 0 cares about relative price of claims across states and currencies. The transverality condition stipulates that all period 0 transactions must be balanced: payment for claims issued must equal payment for claims received. The household Lagrangian is:

$\mathcal{L}_{i}=\sum_{t=1}^{\infty} \beta^{t} \operatorname{Pr}\left(s_{t}\right)\left\{U_{i}\left(C\left(s_{t}\right)\right)-V_{i}\left(N\left(s_{t}\right)\right)+\frac{\lambda_{i}\left(s_{t}\right)}{P_{i}\left(s_{t}\right)}\left[W_{i}\left(s_{t}\right) N_{i}\left(s_{t}\right)+\int_{0}^{1} \mathcal{E}_{i j}\left(s_{t}\right) B_{i j}\left(s_{t}\right) d j-C_{i}\left(s_{t}\right) P_{i}\left(s_{t}\right)\right]\right\}-$ $\lambda_{i 0} \sum_{t=1}^{\infty} \sum_{s t} \int_{0}^{1} q_{j}\left(s_{t}\right) B_{i j}\left(s_{t}\right) d j$

Now take the FOC with respect to state contingent bonds $B_{i j}\left(s_{t}\right)$ :

$$
\frac{\partial \mathcal{L}_{i}}{\partial B_{i j}\left(s_{t}\right)}=\lambda_{i 0} q_{j}\left(s_{t}\right)+\frac{\beta^{t} \lambda_{i}\left(s_{t}\right) \operatorname{Pr}\left(s_{t}\right) \mathcal{E}_{i j}\left(s_{t}\right)}{P_{i}\left(s_{t}\right)}=0
$$

which gives price of the state-contingent bond,

$$
q_{j}\left(s_{t}\right)=\beta^{t} \frac{\lambda_{i}\left(s_{t}\right) \operatorname{Pr}\left(s_{t}\right) \mathcal{E}_{i j}\left(s_{t}\right)}{\lambda_{i 0} P_{i}\left(s_{t}\right)}
$$

The analogous FOC for country $j, \frac{\partial \mathcal{L}_{j}}{\partial B_{j j}\left(s_{t}\right)}=0$ will yield:

$$
q_{j}\left(s_{t}\right)=\beta^{t} \frac{\lambda_{j}\left(s_{t}\right) \operatorname{Pr}\left(s_{t}\right) \mathcal{E}_{j j}\left(s_{t}\right)}{\lambda_{j 0} P_{j}\left(s_{t}\right)}
$$


Using $\mathcal{E}_{j j}\left(s_{t}\right)=1$ and setting (A.4) equal to (A.5), we get the risk-sharing condition

$$
\frac{\lambda_{i}\left(s_{t}\right)}{\lambda_{j}\left(s_{t}\right)}=\frac{\lambda_{i 0}}{\lambda_{j 0}} \frac{P_{i}\left(s_{t}\right)}{P_{j}\left(s_{t}\right) \mathcal{E}_{i j}\left(s_{t}\right)} .
$$

When PPP holds, $\frac{P_{i}\left(s_{t}\right)}{P_{j}\left(s_{t}\right) \mathcal{E}_{i j}\left(s_{t}\right)}=1$, and the risk-sharing condition simplifies to $\frac{\lambda_{i}\left(s_{t}\right)}{\lambda_{j}\left(s_{t}\right)}=\left(\frac{C_{i}\left(s_{t}\right)}{C_{j}\left(s_{t}\right)}\right)^{-\sigma}=$ $\frac{\lambda_{i 0}}{\lambda_{j 0}}$. When the consumption ratio is constant across countries, $C_{i t}=A_{i} C_{w t}$.

In order to solve for $A_{i}$, we substitute (A.4) into the transversality condition.

$$
\begin{aligned}
\sum_{t=1}^{\infty} \sum_{s_{t}} \int_{0}^{1} q_{j}\left(s_{t}\right) B_{i j}\left(s_{t}\right) d j & =\sum_{t=1}^{\infty} \sum_{s_{t}} \int_{0}^{1} \beta^{t} \frac{\lambda_{i}\left(s_{t}\right) \operatorname{Pr}\left(s_{t}\right) \mathcal{E}_{i j}\left(s_{t}\right)}{\lambda_{i 0} P_{i}\left(s_{t}\right)} B_{i j}\left(s_{t}\right) d j \\
& =\sum_{t=1}^{\infty} \sum_{s_{t}} \beta^{t} \frac{\lambda_{i}\left(s_{t}\right) \operatorname{Pr}\left(s_{t}\right)}{\lambda_{i 0} P_{i}\left(s_{t}\right)} \int_{0}^{1} \mathcal{E}_{i j}\left(s_{t}\right) B_{i j}\left(s_{t}\right) d j \\
& \stackrel{(\text { A.1 })}{=} \sum_{t=1}^{\infty} \sum_{s_{t}} \beta^{t} \frac{\lambda_{i}\left(s_{t}\right) \operatorname{Pr}\left(s_{t}\right)}{\lambda_{i 0} P_{i}\left(s_{t}\right)}\left(P_{i}\left(s_{t}\right) C_{i}\left(s_{t}\right)-W_{i}\left(s_{t}\right) N_{i}\left(s_{t}\right)\right) \\
& =0
\end{aligned}
$$

Now substitute $C_{i}\left(s_{t}\right)=A_{i} C_{w}\left(s_{t}\right)$ into the above equation, and solve for $A_{i}$.

$$
\begin{aligned}
A_{i}= & \frac{\sum_{t=0}^{\infty} \sum_{s_{t}} \beta^{t} \frac{W\left(s_{t}\right) N\left(s_{t}\right)}{P\left(s_{t}\right)} \lambda_{i}\left(s_{t}\right) \operatorname{Pr}\left(s_{t}\right)}{\sum_{t=0}^{\infty} \sum_{s_{t}} \beta^{t} C_{w}\left(s_{t}\right) \lambda_{i}\left(s_{t}\right) \operatorname{Pr}\left(s_{t}\right)} \\
= & \frac{\sum_{t=0}^{\infty} \beta^{t} \mathbb{E}_{t}\left\{\frac{W_{t} N_{t}}{P_{t}} \lambda_{i}\left(s_{t}\right)\right\}}{\sum_{t=0}^{\infty} \beta^{t} \mathbb{E}_{t}\left\{C_{w t} \lambda_{i}\left(s_{t}\right)\right\}} \\
= & \frac{\sum_{t=0}^{\infty} \beta^{t} \mathbb{E}_{t}\left\{Y_{i t}^{\frac{\gamma-1}{\gamma}} C_{w t}^{\frac{1}{\gamma}} \lambda_{i}\left(s_{t}\right)\right\}}{\sum_{t=0}^{\infty} \beta^{t} \mathbb{E}_{t}\left\{C\left(w_{t}\right) \lambda_{i}\left(s_{t}\right)\right\}} \\
= & \frac{\sum_{t=0}^{\infty} \beta^{t} \mathbb{E}_{t}\left\{Y_{i t}^{\frac{\gamma-1}{\gamma}} C_{w t}^{\frac{1}{\gamma}} C_{w t}^{-\sigma}\right\}}{\sum_{t=0}^{\infty} \beta^{t} \mathbb{E}_{t}\left\{C\left(w_{t}\right) C_{w t}^{-\sigma}\right\}}
\end{aligned}
$$

where we used $\lambda_{i}\left(s_{t}\right)=A_{i}^{-\sigma} C_{w}^{-\sigma}\left(s_{t}\right)$.

\subsection{Global Social Planner}

Proposition 1 The global social planner will maximize utility weighted over all $i$ countries (24), subject to (25) and (26). The solution to this problem will yield the Pareto efficient 
allocation, detailed below:

$$
\begin{aligned}
& \mathbb{E}\left\{U_{i}\right\}=C_{i}^{1-\sigma}\left(\frac{1}{1-\sigma}-\frac{1}{1+\varphi}\right) \\
& C_{i}=\left(\frac{1}{\chi}\right)^{\frac{1}{\sigma+\varphi}} Z_{w}^{\frac{1+\varphi}{\sigma+\varphi}}, \\
& N_{i}=\left(\frac{1}{\chi}\right)^{\frac{1}{\sigma+\varphi}} Z_{w}^{\frac{(1-\gamma \sigma)(1+\varphi)}{(1+\gamma \varphi)(\sigma+\varphi)}} Z_{i}^{\frac{\gamma-1}{1+\gamma \varphi}}, \\
& Y_{i}=\left(\frac{1}{\chi}\right)^{\frac{1}{\sigma+\varphi}} Z_{w}^{\frac{(1-\gamma \sigma)(1+\varphi)}{(1+\gamma \varphi)(\sigma+\varphi)}} Z_{i}^{\frac{\gamma(1+\varphi)}{1+\gamma \varphi}} \\
& Z_{w}=\left(\int_{0}^{1} Z_{i}^{\frac{(\gamma-1)(1+\varphi)}{1+\gamma \varphi}} d i\right)^{\frac{1+\gamma \varphi}{(\gamma-1)(1+\varphi)}} .
\end{aligned}
$$

Proof: If we substitute (25) and (26) directly into the objective function (24), then we can reformulate the problem as follows:

$$
\max _{\forall c_{i j}} \int_{0}^{1}\left[\frac{\left(\int_{0}^{1} c_{i j}^{\frac{\gamma-1}{\gamma}} d j\right)^{\frac{\gamma(1-\sigma)}{\gamma-1}}}{1-\sigma}-\frac{\chi}{1+\varphi}\left(\frac{\int_{0}^{1} c_{j i} d j}{Z_{i}}\right)^{1+\varphi}\right] d i
$$

Rearranging, we have

$$
\max _{c_{i j}} \frac{1}{1-\sigma} \int_{0}^{1}\left(\int_{0}^{1} c_{i j}^{\frac{\gamma-1}{\gamma}} d j\right)^{\frac{\gamma(1-\sigma)}{\gamma-1}} d i-\frac{\chi}{1+\varphi} \int_{0}^{1} \frac{\left(\int_{0}^{1} c_{j i} d j\right)^{1+\varphi}}{Z_{i}^{1+\varphi}} d i
$$

The FOC with respect to $c_{i j}$ is

$$
0=\left(\int_{0}^{1} c_{i j}^{\frac{\gamma-1}{\gamma}} d j\right)^{\frac{\gamma(1-\sigma)}{\gamma-1}-1} c_{i j}^{\frac{-1}{\gamma}}-\chi \frac{\left(\int_{0}^{1} c_{j i} d j\right)^{\varphi}}{Z_{j}^{1+\varphi}}
$$

This is equivalent to

$$
\begin{aligned}
0 & =\underbrace{\left[\left(\int_{0}^{1} c_{i j}^{\frac{\gamma-1}{\gamma}} d j\right)^{\frac{1-\sigma \gamma}{\gamma-1}}\right]}_{=C_{i}^{\frac{1-\sigma \gamma}{\gamma}}} c_{i j}^{\frac{-1}{\gamma}}-\chi \underbrace{\left(\frac{\int_{0}^{1} c_{j i} d j}{Z_{j}}\right)^{\varphi}}_{=N_{j}^{\varphi}} \frac{1}{Z_{j}}, \\
\Rightarrow 0 & =C_{i}^{\frac{1-\sigma \gamma}{\gamma}} c_{i j}^{-\frac{1}{\gamma}}-\chi \frac{N_{j}^{\varphi}}{Z_{j}},
\end{aligned}
$$


and solving for $c_{i j}$ we have:

$$
c_{i j}=\frac{Z_{j}^{\gamma} C_{i}^{1-\gamma \sigma}}{\chi^{\gamma} N_{j}^{\gamma \varphi}} .
$$

The consumption basket in country $i\left(C_{i}\right)$ can then be expressed as:

$$
\begin{aligned}
C_{i} & =\left(\int_{0}^{1} c_{i j}^{\frac{\gamma-1}{\gamma}} d j\right)^{\frac{\gamma}{\gamma-1}}, \\
& =\left[\int_{0}^{1}\left(\frac{Z_{j}^{\gamma} C_{i}^{1-\gamma \sigma}}{\chi^{\gamma} N_{j}^{\gamma \varphi}}\right)^{\frac{\gamma-1}{\gamma}} d j\right]^{\frac{\gamma}{\gamma-1}}, \\
& =\left(\frac{1}{\chi}\right)^{\frac{1}{\sigma}}\left[\int_{0}^{1}\left(\frac{Z_{j}}{N_{j}^{\varphi}}\right)^{(\gamma-1)} d j\right]^{\frac{1}{\sigma(\gamma-1)}} .
\end{aligned}
$$

So $C_{i}$ does not depend on its own technology $Z_{i}$. Now, let's solve for labor $\left(N_{i}\right)$ and output $\left(Y_{i}\right)$.

$$
\begin{array}{rlr}
N_{i} & =\frac{Y_{i}}{Z_{i}} & \text { from goods market clearing } \\
& =\frac{\int_{0}^{1} c_{j i} d j}{Z_{i}} & \text { from }(26) \\
& =\frac{\int_{0}^{1}\left(\frac{Z_{i}^{\gamma} C_{j}^{1-\gamma \sigma}}{\chi^{\gamma} N_{i}^{\gamma \varphi}}\right) d j}{Z_{i}} & \text { from }(A .11) \\
& =\frac{Z_{i}^{\gamma-1}}{\chi^{\gamma} N_{i}^{\gamma \varphi}} \int_{0}^{1} C_{j}^{1-\gamma \sigma} d j &
\end{array}
$$

From (A.12), we know that $C_{i}=C_{j}=C$ for all $i, j$. So we can take $C_{j}$ outside of the integral in (A.13) and solve for $N_{i}$ :

$$
\begin{aligned}
N_{i} & =\frac{Z_{i}^{\gamma-1} C_{j}^{1-\gamma \sigma}}{\chi^{\gamma} N_{i}^{\gamma \varphi}} \\
\Rightarrow N_{i} & =\left(\frac{Z_{i}^{\gamma-1} C^{1-\gamma \sigma}}{\chi^{\gamma}}\right)^{\frac{1}{1+\gamma \varphi}} .
\end{aligned}
$$

Similarly, output will be:

$$
Y_{i}=\left(\frac{Z_{i}^{\gamma(1+\varphi)} C^{1-\gamma \sigma}}{\chi^{\gamma}}\right)^{\frac{1}{1+\gamma \varphi}}
$$


Substitute (A.14) and (A.15) back into the definition of the consumption basket (A.12), and solve for the consumption basket $C$ in each country, which will be identical:

$$
\begin{aligned}
C & =\left(\frac{1}{\chi}\right)^{\frac{1}{\sigma}}\left\{\int_{0}^{1}\left[\left(\frac{Z_{j}^{\gamma-1} C^{1-\gamma \sigma}}{\chi^{\gamma}}\right)^{\frac{1}{1+\gamma \varphi}}\right]^{-(\gamma-1) \varphi} Z_{j}^{\gamma-1} d j\right\}^{\frac{1}{\sigma(\gamma-1)}}, \\
C^{\frac{\sigma+\varphi}{(1+\gamma \varphi) \sigma}} & =\left(\frac{1}{\chi}\right)^{\frac{1}{\sigma}}\left[\int_{0}^{1}\left(\frac{Z_{j}^{\gamma-1}}{\chi^{\gamma}}\right)^{-\frac{(\gamma-1) \varphi}{1+\gamma \varphi}} Z_{j}^{\gamma-1} d j\right]^{\frac{1}{\sigma(\gamma-1)}}, \\
\Rightarrow C & =C_{i}=\left(\frac{1}{\chi}\right)^{\frac{1}{\sigma+\varphi}}\left(\int_{0}^{1} Z_{j}^{\frac{(\gamma-1)(1+\varphi)}{1+\gamma \varphi}} d j\right)^{\frac{1+\gamma \varphi}{(\sigma+\varphi)(\gamma-1)}} .
\end{aligned}
$$

Solve for labor and output by substituting (A.16) into (A.14) and (A.15) respectively:

$$
\begin{aligned}
& N_{i}=\left(\frac{1}{\chi}\right)^{\frac{1}{\sigma+\varphi}}\left(\int_{0}^{1} Z_{j}^{\frac{(\gamma-1)(1+\varphi)}{1+\gamma \varphi}} d j\right)^{\frac{1-\gamma \sigma}{(\sigma+\varphi)(\gamma-1)}} Z_{i}^{\frac{\gamma-1}{1+\gamma \varphi}} \\
& Y_{i}=\left(\frac{1}{\chi}\right)^{\frac{1}{\sigma+\varphi}}\left(\int_{0}^{1} Z_{j}^{\frac{(\gamma-1)(1+\varphi)}{1+\gamma \varphi}} d j\right)^{\frac{1-\gamma \sigma}{(\sigma+\varphi)(\gamma-1)}} Z_{i}^{\frac{\gamma(1+\varphi)}{1+\gamma \varphi}}
\end{aligned}
$$

This is the Pareto efficient allocation. When $\gamma \rightarrow \infty$, the flexible price allocation and the global social planner allocation become identical. Consumption is identical to the first order between social planner and flexible price allocation. However, it is not true for labor.

\subsection{Flexible Exchange Rates or Currency Union With Contingent Fiscal Policy}

Propositions 2 and 3 give flexible exchange rate allocations and are provided in the text. Here we provide analogous propositions for contingent fiscal policy within a currency union.

\section{Proof of Propositions 2, 3 and 6}

Below, we outline the proof for Propositions 2 and 3. Non-cooperative central banks will maximize their objective function

$$
\max _{N_{i t}} \mathbb{E}_{t-1}\left\{\frac{C_{i t}^{1-\sigma}}{1-\sigma}-\chi \frac{N_{i t}^{1+\varphi}}{1+\varphi}\right\}
$$


subject to the following constraints:

$$
\begin{gathered}
1=\left(\frac{\chi \mu}{1-\tau_{i}}\right) \frac{\mathbb{E}_{t-1}\left\{N_{i t}^{1+\varphi}\right\}}{\mathbb{E}_{t-1}\left\{C_{i t}^{-\sigma} Y_{i t}^{\frac{\gamma-1}{\gamma}} C_{w t}^{\frac{1}{\gamma}}\right\}}, \\
Y_{i t}=Z_{i t} N_{i t}, \\
C_{w t}=\left(\int_{0}^{1} Y_{i t}^{\frac{\gamma-1}{\gamma}}\right)^{\frac{\gamma}{\gamma-1}} \cdot \\
C_{i t}=C_{w t}^{\frac{1}{\gamma}} \mathbb{E}_{t-1}\left\{Y_{i t}^{\frac{\gamma-1}{\gamma}}\right\} \\
C_{i t}=C_{w t}^{\frac{1}{\gamma}} Y_{i t}^{\frac{\gamma-1}{\gamma}}
\end{gathered}
$$

where (A.23a) refers to goods market clearing under complete markets, while (A.23b) refers to goods market clearing under financial autarky. We can formulate a Lagrangian for the non-cooperative and cooperative cases:

$$
\mathcal{L}=\frac{\mathbb{E}_{t-1}\left\{C_{i t}^{1-\sigma}\right\}}{1-\sigma}-\chi \frac{\mathbb{E}_{t-1}\left\{N_{i t}^{1+\varphi}\right\}}{1+\varphi}+\lambda_{i}\left(\mathbb{E}_{t-1}\left\{C_{i t}^{1-\sigma}\right\}-\frac{\chi \mu}{1-\tau_{i}} \mathbb{E}_{t-1}\left\{N_{i t}^{1+\varphi}\right\}\right)
$$

Using $C_{i t}=C_{w t}^{\frac{1}{\gamma}} \mathbb{E}_{t-1}\left\{N_{i t}^{\frac{\gamma-1}{\gamma}} Z_{i t}^{\frac{\gamma-1}{\gamma}}\right\}$ for complete markets, or $C_{i t}=C_{w t}^{\frac{1}{\gamma}} N_{i t}^{\frac{\gamma-1}{\gamma}} Z_{i t}^{\frac{\gamma-1}{\gamma}}$ for financial autarky, we can take the first order condition with respect to $N_{i t} \cdot{ }^{15}$ The FOC will be identical in both cases.

$$
\frac{\partial \mathcal{L}}{\partial N_{i t}}=C_{i t}^{-\sigma}\left(1+\lambda_{i}(1-\sigma)\right)\left(\frac{\gamma-1}{\gamma}\right)\left(\frac{Y_{i t}^{\frac{\gamma-1}{\gamma}} C_{w t}^{\frac{1}{\gamma}}}{N_{i t}}\right)-\chi\left(1+\lambda \frac{\mu}{1-\tau_{i}}(1+\varphi)\right) \frac{1}{N_{i t}} N_{i t}^{1+\varphi}=0
$$

In equilibrium, this equals:

$$
1=\underbrace{\chi\left(\frac{1+\frac{\lambda_{i} \mu(1+\varphi)}{1-\tau_{i}}}{1+\frac{\lambda_{i}(1-\sigma)(\gamma-1)}{\gamma}}\right)}_{\text {Constant }}\left(\frac{N_{i t}^{1+\varphi}}{C_{i t}^{-\sigma} Y_{i t}^{\frac{\gamma-1}{\gamma}} C_{w t}^{\frac{1}{\gamma}}}\right) .
$$

This equation holds in both complete markets and financial autarky, and differs from the flexible

\footnotetext{
${ }^{15}$ Remember that we are optimizing given the fact that state $s_{t}$ is realized. Expectations in our context thus refer to a summation over all possible states multiplied by the probability of each state occuring. For example, $\mathbb{E}_{t-1}\left\{C_{i t}^{1-\sigma}\right\}=\sum_{s_{t}} C_{i}^{1-\sigma}\left(s_{t}\right) \operatorname{Pr}\left(s_{t}\right)$.
} 
price equilibrium only by the constant term. However, subject to labor market clearing, this constant will coincide with the flexible price equilibrium. The flexible price equilibrium in complete markets and financial autarky is found by taking expectations out of the labor market clearing condition (A.20) and substituting in goods market clearing (A.21):

$$
1=\left(\frac{\chi \mu}{1-\tau_{i}}\right) \frac{Y_{i t}^{\frac{1+\varphi \gamma}{\gamma}}}{C_{i t}^{-\sigma} C_{w t}^{\frac{1}{\gamma}} Z_{i t}^{1+\varphi}}
$$

For complete markets, we can express output as a function of technology and a constant term by substituting (A.23a) into (A.27): $Y_{i t}=A_{i} Z_{i t}^{\frac{\gamma(1+\varphi)}{1+\gamma \varphi}}$. (We can do the same for exercise for autarky by substituting (A.23b) into (A.27), but leave that to the reader). Using this expression for output, consumption in complete markets in country $i$ can be expressed as

$$
C_{i t}=A_{i}^{\frac{\gamma-1}{\gamma}} C_{w t}^{\frac{1}{\gamma}} \mathbb{E}_{t-1}\left\{Z_{i t}^{\frac{(\gamma-1)(1+\varphi)}{1+\gamma \varphi}}\right\}
$$

Now substitute (A.28) back into the flexible price equilibrium (A.27)

$$
1=\left(\frac{\chi \mu}{1-\tau_{i}}\right) C_{w t}^{\frac{\sigma}{\gamma}} A_{i}^{\frac{(\gamma-1) \sigma}{\gamma}} \mathbb{E}_{t-1}\left\{Z_{i t}^{\frac{(\gamma-1)(1+\varphi)}{1+\gamma \varphi}}\right\}^{\sigma} A_{i}^{\frac{1+\varphi \gamma}{\gamma}} C_{w t}^{-\frac{1}{\gamma}},
$$

and rearrange and solve for $A_{i}$ :

$$
A_{i}=\left[\left(\frac{1-\tau_{i}}{\chi \mu}\right)^{\gamma} C_{w t}^{1-\sigma} \mathbb{E}_{t-1}\left\{Z_{i t}^{\frac{(\gamma-1)(1+\varphi)}{1+\gamma \varphi}}\right\}^{-\sigma \gamma}\right]^{\frac{1}{1-\sigma+\gamma(\varphi+\sigma)}}
$$

Now, substitute the solution for $A_{i}$, (A.30), into (A.28):

$$
C_{i t}=\left[\left(\frac{\chi \mu}{1-\tau_{i}}\right)^{1-\gamma} C_{w t}^{\varphi+1} \mathbb{E}_{t-1}\left\{Z_{i t}^{\frac{(\gamma-1)(1+\varphi)}{1+\gamma \varphi}}\right\}^{1+\gamma \varphi}\right]^{\frac{1}{1-\sigma+\gamma(\varphi+\sigma)}}
$$

Using the fact that $C_{w t}=\int_{0}^{1} C_{i t} d i=C_{i t}$ in equilibrium, and setting $Z_{w}=\left(\int_{0}^{1} Z_{i t}^{\frac{(\gamma-1)(1+\varphi)}{1+\gamma \varphi}} d i\right)^{\frac{1+\gamma \varphi}{(\gamma-1)(1+\varphi)}}$, integrate (A.31) over all $i$ and solve for consumption for country $i$ in complete markets:

$$
C_{i t}=\left(\frac{1-\tau_{i}}{\chi \mu}\right)^{\frac{1}{\sigma+\varphi}} Z_{w}^{\frac{1+\varphi}{\sigma+\varphi}}
$$

Solving for labor and output using (A.32) is a straightforward exercise. The solution to the 
central bank's problem in complete markets and financial autarky for cooperative and noncooperative equilibria, coincides exactly with the flexible wage allocation. Here we've explicitly outlined the proof for complete markets and for financial autarky with a transfer union. The proof for financial autarky without a transfer union is identical up to (A.27). We simply substitute (A.23b) into (A.27) to get the optimal allocation under financial autarky.

Within a tax union, fiscal authorities will set a labor tax rate of $\tau_{i}=1-\mu$ and there will be no terms of trade manipulation. Outside of a tax union, fiscal authorities will set a labor tax rate of $\tau_{i}=1-\frac{\mu}{\mu_{\gamma}}$, introducing a terms of trade markup to the optimal allocation. In financial autarky, a transfer union will enable replication of the complete markets allocation.

\subsection{Non-Contingent Fiscal Policy Within A Currency Union Proof of Proposition 4 and 5}

In the absence of contingent fiscal policy, the currency union allocation for country $i$ in complete markets can be solved using the five constraints below:

$$
\begin{aligned}
& 1=\left(\frac{\chi \mu}{1-\tau_{i}}\right) \frac{\mathbb{E}_{t-1}\left\{N_{i t}^{1+\varphi}\right\}}{\mathbb{E}_{t-1}\left\{C_{i t}^{-\sigma} Y_{i t}^{\frac{\gamma-1}{\gamma}} C_{w, t}^{\frac{1}{\gamma}}\right\}}, \\
& C_{i t}=C_{w t}^{\frac{1}{\gamma}} \mathbb{E}_{t-1}\left\{Y_{i t}^{\frac{\gamma-1}{\gamma}}\right\}, \\
& Y_{i t}=Z_{i t} N_{i t}, \\
& C_{w t}=\left(\int_{0}^{1} Y_{i t}^{\frac{\gamma-1}{\gamma}}\right)^{\frac{\gamma}{\gamma-1}} .
\end{aligned}
$$

We know that demand for country $i$ 's good is $Y_{i t}=T O T^{-\gamma} C_{w}=\left[\frac{P_{i i}}{C P I_{i}}\right]^{-\gamma} C_{w}$ from (14) and that $P_{i i}=\frac{W_{i}}{Z_{i}}$ from (16). Plugging (16) into (14) gives:

$$
Y_{i t}=\underbrace{\left[\frac{W_{i t}}{C P I_{i t}}\right]^{-\gamma} C_{w}}_{A} Z_{i t}^{\gamma}=A Z_{i t}^{\gamma}
$$

where $A$ is a constant. We can compute labor using $Y_{i t}=Z_{i t} N_{i t}$ :

$$
N_{i t}=A Z_{i t}^{\gamma-1} .
$$


Given the above, consumption will be

$$
C_{i t}=C_{w t}=A\left(\int Z_{i t}^{\gamma-1} d i\right)^{\frac{\gamma}{\gamma-1}}
$$

Using labor market clearing (18), and substituting in $Y_{i t}, C_{i t}, N_{i t}$ expressed as functions of $A$ and $Z_{i t}$ from above, we find:

$$
1=\left(\frac{\chi \mu}{1-\tau_{i}}\right) \frac{A^{1+\varphi} \int_{0}^{1} Z_{i t}^{(\gamma-1)(1+\varphi)} d i}{A^{1-\sigma}\left(\int_{0}^{1} Z_{i t}^{(\gamma-1)} d i\right)^{\frac{\gamma(1-\sigma)}{\gamma-1}}}
$$

Now we can solve for $A$ :

$$
A=\left(\frac{\chi \mu}{1-\tau_{i}}\right)^{\frac{-1}{\sigma+\varphi}}\left(\int_{0}^{1} Z_{i t}^{(\gamma-1)(1+\varphi)} d i\right)^{\frac{-1}{\sigma+\varphi}}\left(\int_{0}^{1} Z_{i t}^{\gamma-1} d i\right)^{\frac{\gamma}{\gamma-1} \frac{(1-\sigma)}{\sigma+\varphi}}
$$

Given this solution for the constant $A$, one can solve for $C_{i t}, N_{i t}$ and $Y_{i t}$ by substituting $A$ into the expressions above. The resulting allocations will be:

$$
\begin{aligned}
\mathbb{E}\left\{U_{i}\right\} & =\mathbb{E}\left\{C_{i}^{1-\sigma}\right\}\left[\frac{1}{1-\sigma}-\frac{1-\tau_{i}}{\mu(1+\varphi)}\right] \\
C_{i} & =C_{w}=\left(\frac{1-\tau_{i}}{\chi \mu}\right)^{\frac{1}{\sigma+\varphi}}\left[\frac{\left(\int_{0}^{1} Z_{i}^{\gamma-1} d i\right)^{\frac{\gamma(1+\varphi)}{\gamma-1}}}{\int_{0}^{1} Z_{i}^{(\gamma-1)(1+\varphi)} d i}\right]^{\frac{1}{\sigma+\varphi}}, \\
N_{i} & =\left(\frac{1-\tau_{i}}{\chi \mu}\right)^{\frac{1}{\sigma+\varphi}}\left[\frac{\left(\int_{0}^{1} Z_{i}^{\gamma-1} d i\right)^{\frac{\gamma(1-\sigma)}{\gamma-1}}}{\int_{0}^{1} Z_{i}^{(\gamma-1)(1+\varphi)} d i}\right]_{i}^{\frac{1}{\sigma+\varphi}} Z_{i}^{\gamma-1}, \\
Y_{i} & =\left(\frac{1-\tau_{i}}{\chi \mu}\right)^{\frac{1}{\sigma+\varphi}}\left[\frac{\left(\int_{0}^{1} Z_{i}^{\gamma-1} d i\right)^{\frac{\gamma(1-\sigma)}{\gamma-1}}}{\int_{0}^{1} Z_{i}^{(\gamma-1)(1+\varphi)} d i}\right]_{i}^{\frac{1}{\sigma+\varphi}} Z^{\gamma}
\end{aligned}
$$

Non-contingent fiscal authorities within a currency union in financial autarky face the fol- 
lowing five constraints:

$$
\begin{aligned}
& 1=\left(\frac{\chi \mu}{1-\tau_{i}}\right) \frac{\mathbb{E}_{t-1}\left\{N_{i t}^{1+\varphi}\right\}}{\mathbb{E}_{t-1}\left\{C_{i t}^{-\sigma} Y_{i t}^{\frac{\gamma-1}{\gamma}} C_{w, t}^{\frac{1}{\gamma}}\right\}}, \\
& C_{i t}=C_{w, t}^{\frac{1}{\gamma}} Y_{i t}^{\frac{\gamma-1}{\gamma}} \\
& Y_{i t}=Z_{i t} N_{i t}, \\
& C_{w t}=\left(\int_{0}^{1} Y_{i t}^{\frac{\gamma-1}{\gamma}}\right)^{\frac{\gamma}{\gamma-1}}, \\
& Y_{i t}=A Z_{i t}^{\gamma} .
\end{aligned}
$$

Conduct the same exercise in financial autarky as in the complete markets case above to solve for the equilibrium allocation in financial autarky:

$$
\begin{gathered}
\mathbb{E}\left\{U_{i}\right\}=\mathbb{E}\left\{C_{i}^{1-\sigma}\right\}\left[\frac{1}{1-\sigma}-\frac{1-\tau_{i}}{\mu(1+\varphi)}\right], \\
C_{i}=C_{w}=\left(\frac{1-\tau_{i}}{\chi \mu}\right)^{\frac{1}{\sigma+\varphi}}\left[\frac{\left(\int_{0}^{1} Z_{i}^{\gamma-1} d i\right)^{\frac{\gamma(1+\varphi)}{\gamma-1}}}{\int_{0}^{1} Z_{i}^{(\gamma-1)(1+\varphi)} d i}\right]^{\frac{1}{\sigma+\varphi}}, \\
N_{i}=\left(\frac{1-\tau_{i}}{\chi \mu}\right)^{\frac{1}{\sigma+\varphi}}\left[\frac{\left(\int_{0}^{1} Z_{i}^{\gamma-1} d i\right)^{\frac{\gamma(1-\sigma)}{\gamma-1}}}{\int_{0}^{1} Z_{i}^{(\gamma-1)(1+\varphi)} d i}\right]_{i}^{\frac{1}{\sigma+\varphi}} Z_{i}^{\gamma-1}, \\
Y_{i}=\left(\frac{1-\tau_{i}}{\chi \mu}\right)^{\frac{1}{\sigma+\varphi}}\left[\frac{\left(\int_{0}^{1} Z_{i}^{\gamma-1} d i\right)^{\frac{\gamma(1-\sigma)}{\gamma-1}}}{\int_{0}^{1} Z_{i}^{(\gamma-1)(1+\varphi)} d i}\right]_{i}^{\frac{1}{\sigma+\varphi}} Z_{i}^{\gamma} .
\end{gathered}
$$

\subsection{Welfare Derivations}

Below, we outline the steps necessary to derive the expected utility functions in Section 6 of the paper. Here, we only conduct the exercise for flexible exchange rates in complete markets. 


$$
\begin{aligned}
C_{\text {flex,complete }} & =\left(\frac{1-\tau_{i}}{\chi \mu}\right)^{\frac{1}{\sigma+\varphi}}\left(\int_{0}^{1} Z_{i}^{\frac{(\gamma-1)(1+\varphi)}{1+\gamma \varphi}} d i\right)^{\frac{1+\gamma \varphi}{(\gamma-1)(\sigma+\varphi)}} \\
\mathbb{E}\left\{U_{\text {flex,complete }}\right\} & =\left[\frac{1}{1-\sigma}-\frac{1-\tau_{i}}{\mu(1+\varphi)}\right] \mathbb{E}\left\{C_{\text {flex }, \text { complete }}^{1-\sigma}\right\} \\
& =\left[\frac{1}{1-\sigma}-\frac{1-\tau_{i}}{\mu(1+\varphi)}\right]\left(\frac{1-\tau_{i}}{\chi \mu}\right)^{\frac{1-\sigma}{\sigma+\varphi}} \mathbb{E}\left\{\left(\int_{0}^{1} Z_{i}^{\frac{(\gamma-1)(1+\varphi)}{1+\gamma \varphi}} d i\right)^{\frac{(1+\gamma \varphi)(1-\sigma)}{(\gamma-1)(\sigma+\varphi)}}\right\}
\end{aligned}
$$

For normative analysis, we assume that technology is log-normally distributed and is independent across time and across countries: $Z_{i t} \sim\left(0, \sigma_{Z}^{2}\right)$. Then the expectation above can be rewritten as:

$$
\begin{aligned}
\mathbb{E}\left\{\left(\int_{0}^{1} Z_{i}^{\frac{(\gamma-1)(1+\varphi)}{1+\gamma \varphi}} d i\right)^{\frac{(1+\gamma \varphi)(1-\sigma)}{(\gamma-1)(\sigma+\varphi)}}\right\} & =e^{\left[\frac{(\gamma-1)(1+\varphi)}{1+\gamma \varphi}\right]^{2} \frac{(1+\gamma \varphi)(1-\sigma)}{(\gamma-1)(\sigma+\varphi)} \sigma_{Z}^{2}} \\
& =e^{\frac{(\gamma-1)(1+\varphi)^{2}(1-\sigma)}{(1+\gamma \varphi)(\sigma+\varphi)} \sigma_{Z}^{2}}
\end{aligned}
$$

Now, we insert this expression back into the original equation and get:

$$
\mathbb{E}\left\{U_{\text {flex,complete }}\right\}=\left[\frac{1}{1-\sigma}-\frac{1-\tau_{i}}{\mu(1+\varphi)}\right]\left(\frac{1-\tau_{i}}{\chi \mu}\right)^{\frac{1-\sigma}{\sigma+\varphi}} e^{\frac{(\gamma-1)(1+\varphi)^{2}(1-\sigma)}{(1+\gamma \varphi)(\sigma+\varphi)} \sigma_{Z}^{2}}
$$

Taking logarithms, we can rewrite the log of expected utility as:

$\log \mathbb{E}\left\{U_{\text {flex,complete }}\right\}=\log \left[\frac{1}{1-\sigma}-\frac{1-\tau_{i}}{\mu(1+\varphi)}\right]+\frac{1-\sigma}{\sigma+\varphi} \log \left(\frac{1-\tau_{i}}{\chi \mu}\right)+\frac{(\gamma-1)(1+\varphi)^{2}(1-\sigma)}{(1+\gamma \varphi)(\sigma+\varphi)} \sigma_{Z}^{2}$.

Calculating the expected utility for the other coalitions simply requires that one follow the steps outlined here. Notice that when we calculate welfare differences between allocations, the first and second terms on the right hand side of equation (A.47) will cancel out, leaving only the difference between the remaining term on the right hand side. 